\title{
DETERMINANTES SOCIOECONÔMICOS, ESTRUTURAS PRODUTIVAS REGIONAIS E CONDIÇÃO OCUPACIONAL NO BRASIL, 2000-2010
}

\author{
Ana Carolina da Cruz lima * \\ Rodrigo Simões ${ }^{\dagger}$ \\ Ana Maria Hermeto ${ }^{\ddagger}$
}

\begin{abstract}
Resumo
O objetivo do artigo é analisar os principais determinantes da condição de ocupação individual. Foram utilizados os microdados dos Censos Demográficos 2000 e 2010 (IBGE) para estimar modelos multinomiais e, assim, identificar em que medida varia a probabilidade de ocupação de indivíduos com características semelhantes, porém, residentes em microrregiões distintas. Os resultados dos modelos demonstram que quanto mais desenvolvida a estrutura produtiva regional, mais complexa é a inserção individual no mercado de trabalho, pois apesar de existirem mais oportunidades emprego, há maior concorrência pelos postos gerados, que tendem a ser intensivos em capital.
\end{abstract}

Palavras-chave: Desenvolvimento Local; Emprego; Modelo Multinomial

\begin{abstract}
The main goal of this paper is to analyze the determinants of the individual employment condition. Using data from the demographic censuses of 2000 and 2010 (IBGE) we estimate multinomial models to verify to what extent the probability of employment of similar individuals varies from a region to another. The results of the models show that the more developed is a region, the more complex is the labor insertion. Despite of existing more labor opportunities in big cities, there are also more competition between individuals in these regions, especially because the new jobs are capital intensive.
\end{abstract}

Keywords: Local Development; Employment; Multinomial Model.

JEL classification: J20, J24, R23

DOI: http://dx.doi .org/10.1590/1413-8050/ea97903

\footnotetext{
* PPGCE/FCE/UERJ. Rio de Janeiro, Rio de Janeiro, Brasil. E-mail: ana.lima@uerj.br

† Cedeplar/UFMG. Belo Horizonte, Minas Gerais, Brasil. E-mail: limoes@cedeplar.ufmg.br

‡ Cedeplar/UFMG. Belo Horizonte, Minas Gerais, Brasil. E-mail: ahermeto@cedeplar.ufmg.br
} 


\section{Introdução}

A análise da dinâmica dos mercados de trabalho brasileiros é bastante discutida no meio acadêmico, principalmente em relação ao seu comportamento nas macrorregiões do país, dadas as diferenças em seus níveis de desenvolvimento. Estudos realizados nessa área procuram demonstrar como as disparidades regionais de renda, originadas no processo de desenvolvimento da economia brasileira e intensificadas em seu período de industrialização recente, refletem-se em diferenciais de salários entre as regiões (ocupações e trabalhadores com características similares são remunerados de forma diferenciada no espaço) e como as características individuais dos trabalhadores, não necessariamente produtivas, influenciam seus níveis de remuneração.

Nesse último caso, destacam-se os trabalhos de Valenzuela (1999), Barros et al. (2007), Soares (2000). Esses autores analisam as diferenças nas oportunidades de trabalho e sua remuneração ao longo do território brasileiro provocadas por questões de gênero e raça. Essas características seriam elementos centrais nesse tipo de análise e, como destacado por Valenzuela (1999, p. $150)$, "estão por trás da construção social da desigualdade e da expressão que esta adquire no mercado de trabalho". Em torno do gênero é estruturada a diferença entre trabalho remunerado (produtivo) e doméstico (reprodutivo), bem como as diferenças dentro do trabalho produtivo entre ocupações e posições de maior prestígio social (que favorece os homens). Ao mesmo tempo, as diferenças no mercado de trabalho baseadas na questão racial refletem-se principalmente nas ocupações: os negros concentram-se nas atividades fundamentalmente manuais e de menor valorização social e remuneração, enquanto os brancos concentram-se, preferencialmente, em atividades mais elaboradas, de maior remuneração e valorização social. Os autores demonstram que desde meados da década de 1980, a posição dos indivíduos negros no mercado de trabalho melhorou, tanto em termos de participação quanto de remuneração, mas essas características ainda implicam piores condições de inserção no mercado. Destacam também que as diferenças de gênero e raça tornam-se mais significativas em funções que exigem maior nível de escolaridade e que no Brasil há forte sensibilidade dos salários em relação ao nível educacional. Assim, a educação torna-se um fator tradicionalmente associado às possibilidades de inserção ocupacional e de mobilidade social. Os autores evidenciam o importante papel que o nível de qualificação pessoal desempenha sobre os diferenciais de salários, entretanto, enfatizam que estas diferenças são insuficientes para explicar esse fenômeno, sendo de fundamental importância considerar as características não produtivas dos indivíduos.

Ramos \& Ferreira (2005), Ramos (2007), Barros et al. (2007), Fontes et al. (2010) avançam nessa análise ao considerarem que a ocupação e os diferenciais de remuneração entre os mercados de trabalho brasileiros também são segmentados no espaço. Ramos \& Ferreira (2005), Ramos (2007) utilizam dados da PNAD para analisar a dinâmica espacial dos mercados de trabalho brasileiros no período subsequente à implantação do Plano Real e na primeira metade da década de 2000. Os autores evidenciam que a realocação espacial dos indivíduos ocupados e desocupados nos mercados de trabalho brasileiros foi bastante heterogênea, especialmente quando são comparadas as dinâmicas das áreas metropolitanas e não metropolitanas, bem como o desempenho das macrorregiões e Unidades da Federação do país. A análise da distribuição do emprego no território permite identificar que a proporção de indivíduos 
ocupados aumentou de forma mais expressiva nas áreas urbanas não metropolitanas do país, bem como nas regiões norte, sudeste e centro-oeste. Em contrapartida, o volume de indivíduos desocupados cresceu de forma mais expressiva nas regiões metropolitanas, especialmente nas regiões sudeste e nordeste.

Barros et al. (2007), por sua vez, utilizam dados da PNAD (1995- 2005) para evidenciar que as diferenças salariais de trabalhadores com características idênticas e empregados em atividades similares chegam a $40 \%$ entre as regiões brasileiras. Essas diferenças existem porque homens e mulheres, negros e brancos, são remunerados de forma diferenciada, inclusive no espaço, apesar de serem perfeitamente substituíveis no processo de produção. Em análise convergente, Fontes et al. (2010) estimam modelos hierárquicos a partir de dados censitários (1991 e 2000) para mensurar a influência das aglomerações urbanas e das estruturas produtivas locais sobre os salários nas cidades médias e regiões metropolitanas brasileiras. Os autores identificam a manutenção de disparidades no rendimento médio do trabalho de indivíduos com características produtivas e não produtivas similares, todavia, residentes em centros urbanos localizados em diferentes regiões do Brasil. Os resultados dos modelos indicam que as disparidades regionais (estruturas produtivas, nível de escolaridade, etc.) se refletem em dinâmicas diferenciadas dos mercados de trabalho e, consequentemente, em diferentes níveis salariais e ocupacionais.

Uma justificativa para os resultados encontrados por todos esses autores (Ramos \& Ferreira 2005, Ramos 2007, Barros et al. 2007, Fontes et al. 2010) reside na desigual distribuição das atividades produtivas no país e nos impactos das mudanças estruturais pós-1990 (abertura comercial e reestruturação produtiva) sobre as mesmas. Por esse motivo é importante compreender os fatores que levam as atividades a se aglomerarem em determinadas regiões, tornando-as mais dinâmicas e, consequentemente, estimulando seus níveis salariais médios e taxas de ocupação e desemprego. A perspectiva adotada neste artigo para explicar essa dinâmica foi elaborada pelos teóricos da Economia Urbana, mais especificamente por Henderson (1988), Glaeser (1999). Esses estudiosos utilizam o conceito de economias externas, relacionadas a spillovers tecnológicos, para explicar os fatores que podem favorecer a concentração espacial das atividades produtivas. Essas externalidades são classificadas como economias de localização e de urbanização. No primeiro caso, as firmas são beneficiadas pela concentração de firmas da mesma indústria ou indústrias similares em determinado centro urbano, como destacado por Marshall (1982) - economias externas às firmas, mas internas à aglomeração. No segundo caso, as firmas são beneficiadas pela diversificação produtiva, pela própria escala urbana e pela oferta de serviços sofisticados à produção, como evidenciado por Jacobs (1969) - economias internas à indústria e à localidade, mas externas às firmas. Assim, nos grandes centros urbanos há uma quantidade elevada de firmas e trabalhadores e uma oferta diversificada de serviços produtivos, o que cria um ambiente propício à inovação e favorece o surgimento de novas atividades. Estas, por sua vez, incentivam o desenvolvimento do sistema de transportes, das comunicações, de atividades financeiras, etc., o que torna esses centros extremamente atraentes do ponto de vista da produção e do consumo. A diversidade implica maior flexibilidade e adequação às mudanças, o que torna a economia menos vulnerável ${ }^{1}$.

\footnotetext{
${ }^{1} \mathrm{~A}$ aglomeração é acompanhada por deseconomias, relacionadas aos custos de deslocamento
} 
Nesse contexto, o artigo procura avaliar a influência das características locais sobre a dinâmica de seus respectivos mercados de trabalho, sem desconsiderar as particularidades dos indivíduos. A ideia subjacente é que maiores níveis de desenvolvimento implicam alterações nas estruturas produtivas em prol de atividades de alto teor tecnológico e do setor terciário, o que provavelmente afeta sua estrutura ocupacional. O objetivo é analisar a probabilidade dos indivíduos estarem ou não ocupados de acordo com suas características, produtivas e não produtivas, considerando-os no espaço - representado por variáveis indicadoras do nível de desenvolvimento socioeconômico da localidade de residência (microrregiões brasileiras). Para sua consecução, serão estimados modelos multinomiais para avaliar a influência desses fatores sobre a probabilidade de ocupação, desocupação e inatividade individual. As informações utilizadas para a análise foram obtidas a partir dos microdados dos Censos Demográficos de 2000 e 2010, elaborados pelo Instituto Brasileiro de Geografia e Estatística (IBGE). A análise dos resultados dos modelos evidencia as diferenças existentes entre homens e mulheres e a importância das estruturas regionais para a situação ocupacional individual: quanto mais desenvolvida uma região, mais complexa é a inserção no mercado de trabalho, pois apesar de existirem maiores oportunidades emprego, há maior concorrência pelos postos gerados (excesso de mão de obra provocado pela atratividade dos grandes centros urbanos), que tendem a ser intensivos em capital. A qualificação individual (educação) continua a ser a medida mais eficaz para contrabalançar essa tendência, especialmente para as mulheres.

$\mathrm{O}$ trabalho possui mais três seções além desta introdução. A metodologia e a base de dados utilizadas são descritas na segunda seção. Os resultados dos modelos são analisados na terceira seção. Em seguida, são realizadas as considerações finais.

\section{Metodologia e Base de Dados}

A problemática que o artigo se propõe a analisar — a condição de ocupação individual - é representada por uma variável categórica que assume três possibilidades mutuamente excludentes: 00 (zero) para indivíduos inativos, ou seja, que não tinham ocupação e não haviam procurado trabalho na data de referência dos censos; 01 (hum) para indivíduos ativos e ocupados; e 02 (dois) para indivíduos ativos e desocupados, ou seja, que haviam procurado emprego na data de referência dos censos, mas não possuíam ocupação. O procedimento econométrico escolhido para analisar essa condição é o modelo de regressão logística multinomial, cujas principais propriedades são descritas detalhadamente por Cameron \& Trivedi (2005). O método de estimação adotado é a Máxima Verossimilhança e os resultados do modelo são interpretados a partir de suas razões relativas de risco (odds ratio). As odds ratio demonstram a mudança relativa nas probabilidades das categorias analisadas, ou seja, elas informam como a probabilidade de escolher a categoria de contraste relativamente à alternativa de referência muda quando determinada variável independente

e às desamenidades urbanas (poluição, criminalidade, exclusão social, elevação da renda fundiária, aceleração da migração interna, aumento do desemprego e subemprego urbanos etc.), que contrabalançam a concentração. Todavia, estas não impedem o desenvolvimento urbano; apenas reduzem seu ritmo de expansão (Henderson 1988). A cidade é o elemento chave deste processo, pois nela são criadas as melhores condições para a troca de informações e o fluxo de produtos e serviços. A cidade representa o equilíbrio entre as forças aglomerativas e de dispersão. 
aumenta uma unidade. Assim, a variável $X$ aumenta (diminui) a probabilidade de que a alternativa $j$ seja escolhida ao invés da alternativa de referência se a odds ratio for maior (menor) que 01 . O objetivo é identificar a probabilidade de ocupação, desocupação e inatividade dos indivíduos de acordo com suas características e as características do local de residência.

\subsection{Fonte de dados}

A base de dados utilizada para a estimação dos modelos foi construída a partir dos microdados dos Censos Demográficos 2000 e 2010, fornecidos pelo IBGE. As informações presentes nos censos demográficos englobam diversas características socioeconômicas da população brasileira e de seus respectivos locais de residência, incluindo aspectos demográficos, educacionais, de trabalho e rendimento, migração, habitação e fecundidade. Em relação à abrangência geográfica, os censos demográficos possuem elevado grau de desagregação, tornando possíveis análises em pequenas escalas espaciais.

A amostra selecionada para o trabalho é composta por indivíduos agrupados em 557 unidades espaciais, referentes às microrregiões geográficas brasileiras (exceto Fernando de Noronha). Considerando o objetivo proposto, foram realizadas algumas restrições amostrais para garantir uma homogeneidade mínima ao perfil dos indivíduos analisados e, consequentemente, facilitar a interpretação dos impactos da estrutura econômica local sobre a condição de ocupação dos indivíduos.

Em primeiro lugar, foram excluídos os indivíduos com idade inferior a 25 anos e superior a 64 anos. Esse recorte etário tem duas justificativas: a primeira refere-se à necessidade de excluir da amostra indivíduos em idade escolar, que ainda não completaram o seu ciclo educacional e que possuem comportamentos específicos relacionados ao ingresso inicial no mercado de trabalho; a segunda refere-se à necessidade de excluir indivíduos que possuem maior probabilidade de inatividade, por já terem ultrapassado o limite superior do tempo de contribuição previdenciária.

Com o intuito de minimizar comportamentos muito heterogêneos, também foram excluídos da análise indivíduos residentes em áreas rurais. A importância de excluir o setor rural da análise é explicada pela elevada disparidade entre os mercados de trabalho rurais e urbanos no Brasil em termos de taxas de ocupação, desocupação e informalidade, bem como pela ênfase teórica adotada no artigo. Ao supor que o desenvolvimento local e a diversificação produtiva das cidades têm impactos significativos sobre as estruturas ocupacionais, os autores optam por priorizar a análise dos mercados de trabalho urbanos no Brasil.

Ajustes adicionais, como a exclusão de indivíduos que se autodeclararam indígenas e/ou amarelos e residentes em domicílios coletivos, improvisados ou sem chefe, foram realizados para minimizar possíveis erros de estimação.

Adicionalmente aos recortes realizados, a amostra foi dividida em dois grupos: homens e mulheres. A razão para essa divisão refere-se às diferenças de gênero que existem nos mercados de trabalho brasileiros, destacadas na introdução, que tendem a favorecer indivíduos do sexo masculino. A decisão de estimar modelos específicos para cada grupo tem como objetivo aumentar o poder explicativo das variáveis baseadas em características da estrutura produtiva local, auxiliando a identificação da segmentação regional dos mercados de trabalho. 
Os fatores que influenciam a inserção de um indivíduo no mercado de trabalho podem ser classificados, a priori, em duas grandes categorias. A primeira está associada às características dos próprios indivíduos (condições socioeconômicas) e a segunda às características do ambiente em que os mesmos estão inseridos (infraestrutura econômica, institucional, composição da força de trabalho, etc.). Além disso, ressalta-se que a condição de migração individual é inserida na análise com o intuito de captar um possível viés de seleção nos mercados de trabalho brasileiros, uma vez que os migrantes são positivamente selecionados (mais jovens e mais escolarizados) e tendem a possuir maior probabilidade de inserção ocupacional, conforme evidenciam Lima et al. $(2011)^{2}$. As duas primeiras tabelas descrevem as variáveis indicadoras de atributos pessoais incluídas na análise:

Tabela 1: Variável Dependente

\begin{tabular}{lll}
\hline Variável & Nome & Descrição \\
\hline sitocup & Situação Ocupacional & Variável categórica que assume \\
& & o valor 0 para indivíduos ina- \\
& tivos, 1 para indivíduos ativos \\
& & e ocupados e 2 para indivíduos \\
& ativos e desocupados. \\
\hline
\end{tabular}

Fonte: elaboração própria a partir dos microdados dos Censos

Demográficos 2000 e 2010.

Foram criados 08 (oito) indicadores para evidenciar a dinâmica socioeconômica das microrregiões brasileiras entre 2000 e 2010, cujas descrições podem ser observadas na tabela 03 abaixo. A construção desses indicadores procurou cobrir aspectos essenciais do processo de desenvolvimento econômico, enfatizando a crescente importância das aglomerações urbanas. A proporção de domicílios com esgotamento sanitário ligado à rede geral é utilizada como proxy da infraestrutura urbana; quanto mais elevada essa proporção, maior a capacidade regional de minimizar os custos de congestionamento das grandes cidades. O valor médio do rendimento domiciliar per capita e a média de anos de estudo evidenciam o nível de crescimento regional, pois valores mais expressivos desses indicadores equivalem a regiões mais atrativas do ponto de vista econômico (há trabalhadores mais qualificados e consumidores com maior potencial de renda disponível).

O grau de industrialização, a oferta de serviços modernos, a proporção da força de trabalho qualificada e a taxa de formalização das ocupações evidenciam o grau de diversidade regional e o aumento da complexidade inerente aos grandes centros urbanos; eles representam o padrão de crescimento das atividades produtivas e o estágio de desenvolvimento urbano. Esses indicadores ajudam a identificar as vantagens e desvantagens da especialização e da

\footnotetext{
${ }^{2}$ Além disso, se a existência de endogeneidade do processo migratório não é considerada na análise, os estimadores obtidos são inconsistentes e possuem viés, pois existe uma relação significativa entre a condição de ocupação individual, a dinâmica produtiva e dos mercados de trabalho locais e a decisão de migrar. Por esse motivo, antes de analisar a probabilidade de um indivíduo estar ou não ocupado é preciso considerar a probabilidade de o mesmo ser migrante, o que é realizado por meio do modelo de Seleção Amostral de Heckman, conforme evidenciam Cameron \& Trivedi (2005). Os resultados do modelo evidenciam que os homens, brancos, jovens, mais escolarizados e que vivem em situação conjugal estável são os indivíduos que apresentam maior probabilidade de efetivar um deslocamento. Ou seja, indivíduos com essas características constituem um grupo que possui maior probabilidade de migrar em comparação aos demais.
} 
Tabela 2: Variáveis explicativas indicadoras de características indivíduais

\begin{tabular}{|c|c|c|}
\hline Variável & Nome & Descrição \\
\hline branco & Branco & $\begin{array}{l}\text { Dummy com valor igual a } 1 \text { se o } \\
\text { indivíduo é branco e } 0 \text { caso con- } \\
\text { trário. }\end{array}$ \\
\hline idade & Idade & Idade em anos. \\
\hline idade 2 & Experiência profissional & $\begin{array}{l}\text { Proxy para experiência profissi- } \\
\text { onal, que é igual ao quadrado da } \\
\text { idade do indivíduo. }\end{array}$ \\
\hline respdom & Responsável pelo domicílio & $\begin{array}{l}\text { Dummy com valor igual a } 1 \text { se } \\
\text { o indivíduo é o responsável pelo } \\
\text { domicílio e } 0 \text { caso contrário. }\end{array}$ \\
\hline pmigrante $^{*}$ & Probabilidade de ser migrante & $\begin{array}{l}\text { Probabilidade de um indivíduo } \\
\text { ser migrante de acordo com suas } \\
\text { características produtivas (anos } \\
\text { de estudo e experiência profis- } \\
\text { sional) e não produtivas (sexo, } \\
\text { idade, cor e área de residência - } \\
\text { rural, urbana ou metropolitana). } \\
\text { Os valores desta variável foram } \\
\text { obtidos a partir da estimação de } \\
\text { um modelo probit para a condi- } \\
\text { ção de migração individual. }\end{array}$ \\
\hline anosest & Anos de estudo & $\begin{array}{l}\text { Quantidade de anos de estudo } \\
\text { do indivíduo. }\end{array}$ \\
\hline metropolitana & Área Metropolitana & $\begin{array}{l}\text { Dummy com valor igual a } 1 \text { se o } \\
\text { indivíduo reside em área metro- } \\
\text { politana e } 0 \text { caso contrário. }\end{array}$ \\
\hline
\end{tabular}

Fonte: elaboração própria a partir dos microdados dos Censos Demográficos 2000 e 2010 .

*) O critério de migração refere-se à data fixa: migrante é o indivíduo que mora há menos de 05 anos na microrregião de recenseamento, ainda que tenha nascido no mesma. Não migrante é o indivíduo que nasceu e sempre morou na localidade ou que mora há pelo menos 05 anos na mesma.

diversificação urbanas destacadas por Duraton \& Puga (2002) e sua influência sobre a inserção ocupacional. Mais especificamente, a oferta de serviços modernos é fundamental para explicar as mudanças econômicas recentes, visto que a mesma tornou-se elemento essencial para o crescimento econômico (a integração entre indústria e serviços reflete os ajustes realizados para manter a competitividade no cenário econômico mundial em constantes transformações). Segundo Marshall \& Wood (1995), os serviços sofisticados concentramse justamente nas regiões mais desenvolvidas, todavia, as ocupações desse ramo tendem a ser cada vez mais seletivas e intensivas em capital, tornando mais complexa a inserção dos trabalhadores.

A taxa de pobreza foi calculada de acordo com as recomendações de Foster et al. (1984) e seu objetivo é identificar como a estagnação econômica de uma região pode afetar a condição de ocupação individual.

Por fim, foram criadas dummies regionais (nordeste, norte, centro-oeste, sul, sudeste e São Paulo), para verificar se há alguma influência macrorregional sobre as probabilidades de ocupação, desocupação e inatividade. 
Tabela 3: Variáveis explicativas indicadoras das características microrregionais

\begin{tabular}{|c|c|c|}
\hline Variável & Nome & Descrição \\
\hline$t x_{e} s g o t$ & Taxa de esgotamento sanitário & $\begin{array}{l}\text { Proporção de domicílios da mi- } \\
\text { crorregião com esgotamento sa- } \\
\text { nitário ligado à rede geral. }\end{array}$ \\
\hline med $_{a}$ nosest & Média de anos de estudo & $\begin{array}{l}\text { Média de anos de estudo da mi- } \\
\text { crorregião. }\end{array}$ \\
\hline grau $_{i}$ nd & Grau de industrialização & $\begin{array}{l}\text { Proporção de pessoas ocupadas } \\
\text { nos setores industriais da mi- } \\
\text { crorregião. }\end{array}$ \\
\hline$o f_{s}$ ervmoder & Oferta de serviços modernos & $\begin{array}{l}\text { Proporção de pessoas ocupadas } \\
\text { em atividades modernas do se- } \\
\text { tor de serviços da mircorregião. }\end{array}$ \\
\hline$f t_{q}$ ualif & Força de trabalho qualificada & $\begin{array}{l}\text { Proporção de pessoas ocupadas } \\
\text { na microrregião que possuem } \\
\text { mais de } 11 \text { anos de estudo. }\end{array}$ \\
\hline$t x_{f}$ ormal & Taxa de trabalho formal & $\begin{array}{l}\text { Proporção de pessoas ocupadas } \\
\text { em atividades formais na micror- } \\
\text { região. }\end{array}$ \\
\hline renddompc $c_{m}$ edio & Rendimento domiciliar per capita médio & $\begin{array}{l}\text { Rendimento domiciliar per ca- } \\
\text { pita médio da microrregião. }\end{array}$ \\
\hline pobreza** & Taxa de pobreza & $\begin{array}{l}\text { Indicador de pobreza da micror- } \\
\text { região }\end{array}$ \\
\hline
\end{tabular}

Fonte: elaboração própria a partir dos microdados dos Censos Demográficos 2000 e 2010.

(*) Os seguintes setores foram classificados como serviços modernos: serviços de telecomunicações, serviços financeiros e seguros, serviços jurídicos, de contabilidade e auditoria, consultorias, publicidade, engenharia e arquitetura, desenho e outros serviços técnico-profissionais prestados a empresas, serviços auxiliares da indústria e instituições científicas e tecnológicas.

${ }^{(* *)}$ A linha de pobreza equivale a 1/4 do salário mínimo vigênte em cada ano censitário. A adoção deste critério é justificada por esta ser a principal referência para a inclusão de indivíduos em programas sociais do Governo Federal.

\section{Situação ocupacional no Brasil urbano: os principais determinantes da escolha individual}

Serão estimados três modelos empíricos de regressão logística multinomial para cada grupo de análise utilizando as variáveis descritas na seção 3.1. O primeiro modelo ( $\mathrm{n}^{\circ} 1 \mathrm{~A}$ para homens e $\mathrm{n}^{\circ} 1 \mathrm{~B}$ para mulheres) inclui apenas as variáveis explicativas indicadoras das características individuais; o segundo modelo ( $\mathrm{n}^{\circ} 2 \mathrm{~A}$ para homens e $\mathrm{n}^{\circ} 2 \mathrm{~B}$ para mulheres) incorpora as variáveis dos atributos regionais, controlando os resultados do modelo numa perspectiva espacial; o terceiro modelo ( $\mathrm{n}^{\circ} 3 \mathrm{~A}$ para homens e $\mathrm{n}^{\circ} 3 \mathrm{~B}$ para mulheres) incorpora dummies macrorregionais com o objetivo de identificar as principais tendências dos mercados de trabalho brasileiros.

\subsection{Análise descritiva das variáveis}

Para contextualizar a discussão é interessante observar algumas características gerais da amostra selecionada para o estudo. A maior parte dos indivíduos que a compõem encontra-se ocupada, e essa proporção aumentou no período 
analisado (de 64,4\% para 70,5\%) todavia, há uma diferença significativa entre o percentual de homens e mulheres que possuem trabalho. Conforme pode ser observado na tabela 04 , a taxa de ocupação masculina é muito superior à feminina e o oposto é válido para a taxa de inatividade. É interessante observar que a proporção de desocupados é relativamente baixa e diminuiu no período para ambos os grupos, o que parece indicar que as principais escolhas individuais transitam entre a inatividade e a atividade. É importante ressaltar que os dados evidenciam o aumento da participação feminina nos mercados de trabalho nos anos mais recentes, corroborando estudos sobre o tema.

A maior parte da amostra é composta por indivíduos brancos (mas esse percentual diminuiu de 59,5\% em 2000 para 51,7\% em 2010), responsáveis pelo domicílio (55\%) e não migrantes (90\%). A tabela 5 demonstra a distribuição por sexo de cada uma dessas categorias. Observa-se que os homens continuam a ser os principais responsáveis pelos domicílios brasileiros e que a mobilidade individual parece não ter um recorte por gênero.

Tabela 4: Composição amostral por categoria ocupacional

\begin{tabular}{|c|c|c|c|c|c|c|c|}
\hline \multicolumn{8}{|c|}{2000} \\
\hline & Inativos & \multicolumn{2}{|c|}{ Ativos } & Total & Inativos & \multicolumn{2}{|c|}{ Ativos } \\
\hline & & Ocupados & Desocupados & & & Ocupados & Desocupados \\
\hline Homens & 311310 & 2235432 & 205168 & 2751910 & $11,31 \%$ & $81,23 \%$ & $7,46 \%$ \\
\hline Mulheres & 1245908 & 1418225 & 255888 & 2920021 & $42,67 \%$ & $48,57 \%$ & $8,76 \%$ \\
\hline Total & 1557218 & 3653657 & 461056 & 5671931 & - & - & - \\
\hline \multicolumn{8}{|c|}{2010} \\
\hline & Inativos & \multicolumn{2}{|c|}{ Ativos } & Total & Inativos & \multicolumn{2}{|c|}{ Ativos } \\
\hline & & Ocupados & Desocupados & & & Ocupados & Desocupados \\
\hline Homens & 421431 & 2651098 & 99344 & 3171873 & $13,29 \%$ & $83,58 \%$ & $3,13 \%$ \\
\hline Mulheres & 1256619 & 1994496 & 164063 & 3415178 & $36,80 \%$ & $58,40 \%$ & $4,80 \%$ \\
\hline Total & 1678050 & 4645594 & 263407 & 6587051 & - & - & - \\
\hline
\end{tabular}

Fonte: elaboração própria a partir dos microdados dos Censos Demográficos 2000 e 2010.

A análise descritiva dos indicadores de desenvolvimento local evidencia a problemática regional brasileira. Os desequilíbrios regionais originados no processo de desenvolvimento da economia nacional persistem e os dados utilizados são capazes de mostrar a complexidade desse processo, que ultrapassa a discussão macrorregional. As disparidades de renda, emprego e oportunidades no país diferem não apenas entre suas macrorregiões, mas também em uma escala microrregional. A tabela 6 mostra os valores médios, mínimos e máximos dos indicadores regionais calculados a partir dos microdados dos censos e é possível observar uma grande variabilidade entre os mesmos.

Em todos os casos, observa-se que as microrregiões com melhor desempenho estão localizadas na região centro-sul do país e nas proximidades das capitais das regiões Norte e Nordeste. Foram raríssimos os casos em que os indicadores das microrregiões do Norte-Nordeste ultrapassaram a média nacional. Por outro lado, as microrregiões mais dinâmicas, localizadas especialmente no interior de São Paulo, algumas regiões de Minas Gerais (Metropolitana de Belo Horizonte, Sul e Triângulo), do Paraná (Curitiba, Maringá), de Santa Catarina (Florianópolis, Joinville, Blumenau), do Rio Grande do Sul (Porto Alegre) e do Mato Grosso do Sul, obtiveram valores superiores à média nacional. 
Tabela 5: Distribuição amostral por cor, condição de migração e posição no domicílio, Brasil (20002010)

\begin{tabular}{|c|c|c|c|c|c|c|}
\hline$(\%)$ & Brancos & Pretos ou pardos & Migrantes & Não migrantes & Responsável pelo domicílio & Outros \\
\hline \multicolumn{7}{|c|}{2000} \\
\hline Homens & 47,62 & 49,84 & 50,46 & 48,32 & 75,73 & 14,93 \\
\hline Mulheres & 52,38 & 50,16 & 49,54 & 51,68 & 24,27 & 85,07 \\
\hline Total & 100 & 100 & 100 & 100 & 100 & 100 \\
\hline \multicolumn{7}{|c|}{2010} \\
\hline Homens & 47,58 & 48,76 & 50,14 & 47,98 & 62,21 & 30,55 \\
\hline Mulheres & 52,42 & 51,24 & 49,86 & 52,02 & 37,79 & 69,45 \\
\hline Total & 100 & 100 & 100 & 100 & 100 & 100 \\
\hline
\end{tabular}

Fonte: elaboração própria a partir dos microdados dos Censos Demográficos 2000 e 2010. 
Tabela 6: Valores médios, máximos e mínimos dos indicadores regionais (Brasil, 2000-2010)

\begin{tabular}{lccrr}
\hline \multicolumn{2}{c}{2000} & & & \\
\hline & Média & Desvio padrão & Mínimo & Máximo \\
Taxa de esgoto & 0,4807 & 0,2958 & 0,0000 & 0,9407 \\
Grau de industrialização & 0,1304 & 0,0588 & 0,0188 & 0,4262 \\
Oferta de serviços modernos & 0,1031 & 0,0437 & 0,0000 & 0,2110 \\
Força de trabalho qualificada & 0,2884 & 0,0978 & 0,0309 & 0,5163 \\
Taxa de formalização & 0,3818 & 0,1258 & 0,0287 & 0,5659 \\
Pobreza & 0,3267 & 0,1725 & 0,0851 & 0,8146 \\
Média de anos de estudo & 6,33 & 1,34 & 2,39 & 8,52 \\
Rendimento domiciliar per capita médio* & 440,12 & 189,42 & 99,57 & 881,73 \\
\hline
\end{tabular}

Fonte: elaboração própria a partir dos microdados dos Censos Demográficos 2000 e 2010.

(*) $\mathrm{R} \$ 2010$.

No de microrregiões: 557

Esse recorte macrorregional não excluiu a existência de áreas estagnadas no centro-sul do país, como, por exemplo, o norte de Minas Gerais, microrregiões do Rio de Janeiro, Espírito Santo, Goiás, Mato Grosso e Mato Grosso do Sul (exceto aquelas nucleadas pelas capitais) e localidades do interior do Rio Grande do Sul e do Paraná.

\subsection{Análise dos resultados dos modelos}

A comparação entre as condições de ocupação dos indivíduos é realizada por intermédio das seguintes alternativas:

- $y_{i}=0$ se o indivíduo é inativo;

- $y_{i}=1$ se o indivíduo é ativo e possui ocupação;

- $y_{i}=2$ se o indivíduo é inativo e está desocupado.

A categoria de referência (base) no problema analisado é a inatividade. O objetivo da estimação é avaliar como as características individuais e do local de residência influenciam a condição de ocupação dos indivíduos, visto que as mesmas podem afetar significativamente a inserção no mercado de trabalho.

\section{A escolha ocupacional masculina}

Os resultados da estimação dos modelos multinomiais (razões de riscos relativos) podem ser observados na tabela 7. Como destacado anteriormente, a categoria de referência é inativo, logo, a interpretação dos resultados dos modelos deve considerar a probabilidade de um indivíduo estar ocupado (ou desocupado) em detrimento da inatividade.

Nos três modelos estimados, observa-se que a probabilidade de ocorrência da alternativa ativo e ocupado aumenta, quando comparada à categoria inativo, de acordo com as variáveis idade, responsável pelo domicílio, probabilidade de ser migrante e anos de estudo. Esses resultados indicam que características individuais tradicionalmente beneficiadas pelos mercados de trabalhos, como escolaridade, facilitam a inserção ocupacional. Além disso, a migração tende a favorecer essa inserção, o que parecer confirmar as hipóteses de seletividade do processo migratório — os migrantes, em geral, são 
mais qualificados e empreendedores do que a média da população (Lima et al. 2011). Para visualizar essas considerações observe as estimativas do modelo 03A (completo). É possível perceber que a probabilidade de um indivíduo responsável pelo domicílio estar ocupado é maior do que a de um indivíduo que não ocupa essa posição (aproximadamente 90\% em 2000 e 30\% em 2010); para indivíduos mais velhos os percentuais são, respectivamente, $36 \%$ e $55 \%$; para homens com elevada probabilidade de migração os percentuais são, respectivamente, $52 \%$ e $58 \%$. Nota-se, todavia, que a probabilidade de ocupação não aumenta para indivíduos brancos, o que provavelmente pode ser justificado pela correlação existente entre essa variável e a variável pmigrante, assim como esse resultado pode refletir, em alguma medida, a redução da segmentação dos mercados de trabalho brasileiros em relação à cor dos indivíduos. Além disso, os modelos evidenciam que residir em áreas metropolitanas não implica necessariamente maior facilidade de obter trabalho. Na realidade, o elevado grau de diversificação dos grandes centros urbanos metropolitanos torna mais complexa a dinâmica laboral, exige maior qualificação individual e aumenta a concorrência entre a mão de obra, dificultando o ingresso no mercado de trabalho (odds ratio menores do que 01 ).

A estimação dos modelos $2 \mathrm{~A}$ e $3 \mathrm{~A}$ evidencia que o processo de inserção ocupacional é bastante complexo e depende não apenas dos níveis de qualificação individual, mas também das características das estruturas produtivas regionais. Seus resultados indicam, inclusive, que a migração per se não é capaz de aumentar a inserção individual nos mercados de trabalho, pois a obtenção de novo emprego dependerá não apenas dos atributos individuais, mas também das características produtivas e dos mercados de trabalho das regiões de destino dos migrantes. Em outras palavras, a dinâmica econômica das regiões de destino dos migrantes é essencial para a determinação de seu processo de inserção ocupacional.

Os resultados do modelo $2 \mathrm{~A}$ evidenciam que a residência em áreas mais dinâmicas, com elevados níveis educacionais médios e expressiva densidade urbana, torna mais difícil o processo de inserção ocupacional dos indivíduos. Nessas microrregiões, os mercados de trabalho são caracterizados por expressivos graus de formalização e de participação das atividades do setor de serviços modernos (intensivos em tecnologia e mão de obra especializada), o que implica elevada competição pelas vagas geradas de emprego e, consequentemente, maior dificuldade para a inserção ocupacional dos trabalhadores. As razões de riscos relativos para as variáveis indicadoras dessas características (taxa de esgoto, média de anos de estudo, oferta de serviços modernos e taxa de formalização) são menores do que $01 \mathrm{em}$ todo o período analisado, indicando que a residência nestas localidades diminui a probabilidade de ocupação individual. Esse resultado, que aparentemente é contraditório, evidencia a complexidade inerente aos mercados de trabalho urbanos (já destacada pela variável indicadora de áreas metropolitanas), pois quanto mais densa a localidade, maior a competitividade e apenas indivíduos altamente qualificados obterão sucesso no processo de inserção ocupacional. Ainda em relação às variáveis indicadoras da densidade urbana, observa-se que a razão de riscos relativos para a proporção da força de trabalho qualificada é maior do que 01 em 2000, indicando elevada probabilidade de ocupação para indivíduos residentes em microrregiões com maior parcela da força de trabalho desempenhando atividades técnico-científicas em comparação aos não residentes. Em 2010, todavia, essa variável passa a corroborar os resultados obtidos para os 
Tabela 7: Razão de riscos relativos de regressão logística multinomial para a condição de ocupação individual homens (Brasil, 2000-10)

\begin{tabular}{|c|c|c|c|c|c|c|c|c|c|c|c|c|}
\hline & \multicolumn{6}{|c|}{ Categoria $1=$ ativo e ocupado } & \multicolumn{6}{|c|}{ Categoria 2 = ativo e desocupado } \\
\hline & \multicolumn{2}{|c|}{ Modelo 1A } & \multicolumn{2}{|c|}{ Modelo 2A } & \multicolumn{2}{|c|}{ Modelo 3A } & \multicolumn{2}{|c|}{ Modelo 1A } & \multicolumn{2}{|c|}{ Modelo 2A } & \multicolumn{2}{|c|}{ Modelo 3A } \\
\hline & 2000 & 2010 & 2000 & 2010 & 2000 & 2010 & 2000 & 2010 & 2000 & 2010 & 2000 & 2010 \\
\hline branco & $\begin{array}{l}0,9481^{\text {*** }} \\
(0,0000)\end{array}$ & $\begin{array}{l}0,8576^{* * *} \\
(0,0000)\end{array}$ & $\begin{array}{l}0,9022^{* * *} \\
(0,0000)\end{array}$ & $\begin{array}{l}0,7892^{* * *} \\
(0,0000)\end{array}$ & $\begin{array}{l}0,9061^{* * *} \\
(0,0000)\end{array}$ & $\begin{array}{l}0,7983^{* * *} \\
(0,0000)\end{array}$ & $\begin{array}{l}0,7772^{* * *} \\
(0,0000)\end{array}$ & $\begin{array}{l}0,7276^{* * *} \\
(0,0000)\end{array}$ & $\begin{array}{l}0,7694^{* * *} \\
(0,0000)\end{array}$ & $\begin{array}{l}0,7824^{* * *} \\
(0,0000)\end{array}$ & $\begin{array}{l}0,7683^{* * *} \\
(0,0000)\end{array}$ & $\begin{array}{l}0,7958^{\text {*** }} \\
(0,0000)\end{array}$ \\
\hline idade & $\begin{array}{l}1,3580^{* * *} \\
(0,0000)\end{array}$ & $\begin{array}{l}1,5505^{* * *} \\
(0,0000)\end{array}$ & $\begin{array}{l}1,3597^{* * *} \\
(0,0000)\end{array}$ & $\begin{array}{l}1,5510^{* * * *} \\
(0,0000)\end{array}$ & $\begin{array}{l}1,3600^{* * * *} \\
(0,0000)\end{array}$ & $\begin{array}{l}1,5516^{\text {*** }} \\
(0,0000)\end{array}$ & $\begin{array}{l}1,2098^{* * *} \\
(0,0000)\end{array}$ & $\begin{array}{l}1,2064^{* * * *} \\
(0,0000)\end{array}$ & $\begin{array}{l}1,2091^{* * *} \\
(0,0000)\end{array}$ & $\begin{array}{l}1,2062^{* * *} \\
(0,0000)\end{array}$ & $\begin{array}{l}1,2094^{* * *} \\
(0,0000)\end{array}$ & $\begin{array}{l}1,2069^{* * * *} \\
(0,0000)\end{array}$ \\
\hline idade2 & $\begin{array}{l}0,9965^{* * *} \\
(0,0000)\end{array}$ & $\begin{array}{l}0,9954^{* * *} \\
(0,0000)\end{array}$ & $\begin{array}{l}0,9965^{* * * *} \\
(0,0000)\end{array}$ & $\begin{array}{l}0,9954^{* * *} \\
(0,0000)\end{array}$ & $\begin{array}{l}0,9965^{* * * *} \\
(0,0000)\end{array}$ & $\begin{array}{l}0,9954^{* * *} \\
(0,0000)\end{array}$ & $\begin{array}{l}0,9974^{* * *} \\
(0,0000)\end{array}$ & $\begin{array}{l}0,9974^{* * *} \\
(0,0000)\end{array}$ & $\begin{array}{l}0,9974^{* * *} \\
(0,0000)\end{array}$ & $\begin{array}{l}0,9975^{\text {**** }} \\
(0,0000)\end{array}$ & $\begin{array}{l}0,9974^{* * *} \\
(0,0000)\end{array}$ & $\begin{array}{l}0,9974^{* * *} \\
(0,0000)\end{array}$ \\
\hline respdom & $\begin{array}{l}1,9366^{* * *} \\
(0,0000)\end{array}$ & $\begin{array}{l}1,3124^{* * *} \\
(0,0000)\end{array}$ & $\begin{array}{l}1,9119^{* * *} \\
(0,0000)\end{array}$ & $\begin{array}{l}1,3017^{* * *} \\
(0,0000)\end{array}$ & $\begin{array}{l}1,9127^{* * * *} \\
(0,0000)\end{array}$ & $\begin{array}{l}1,3014^{* * *} \\
(0,0000)\end{array}$ & $\begin{array}{l}1,0125^{* * *} \\
(0,0000)\end{array}$ & $\begin{array}{l}0,9126^{* * * *} \\
(0,0000)\end{array}$ & $\begin{array}{l}1,0159^{* * *} \\
(0,0000)\end{array}$ & $\begin{array}{l}0,9158^{* * *} \\
(0,0000)\end{array}$ & $\begin{array}{l}1,0144^{* * *} \\
(0,0000)\end{array}$ & $\begin{array}{l}0,9156^{* * *} \\
(0,0000)\end{array}$ \\
\hline pmigrante & $\begin{array}{l}1,5236^{* * *} \\
(0,0000)\end{array}$ & $\begin{array}{l}1,5785^{* * *} \\
(0,0000)\end{array}$ & $\begin{array}{l}1,5239^{* * * *} \\
(0,0000)\end{array}$ & $\begin{array}{l}1,5820^{* * * *} \\
(0,0000)\end{array}$ & $\begin{array}{l}1,5234^{* * * *} \\
(0,0000)\end{array}$ & $\begin{array}{l}1,5828^{* * * *} \\
(0,0000)\end{array}$ & $\begin{array}{l}1,2619^{* * *} \\
(0,0000)\end{array}$ & $\begin{array}{l}1,1895^{* * *} \\
(0,0000)\end{array}$ & $\begin{array}{l}1,2627^{* * *} \\
(0,0000)\end{array}$ & $\begin{array}{l}1,1898^{* * * *} \\
(0,0000)\end{array}$ & $\begin{array}{l}1,2618^{* * *} \\
(0,0000)\end{array}$ & $\begin{array}{l}1,1906^{* * * *} \\
(0,0000)\end{array}$ \\
\hline anosest & $\begin{array}{l}1,0277^{* * * *} \\
(0,0000)\end{array}$ & $\begin{array}{l}1,0082^{* * *} \\
(0,0000)\end{array}$ & $\begin{array}{l}1,0296^{* * *} \\
(0,0000)\end{array}$ & $\begin{array}{l}1,0067^{* * * *} \\
(0,0000)\end{array}$ & $\begin{array}{l}1,0300^{* * * *} \\
(0,0000)\end{array}$ & $\begin{array}{l}1,0066^{* * *} \\
(0,0000)\end{array}$ & $\begin{array}{l}0,9567^{* * * *} \\
(0,0000)\end{array}$ & $\begin{array}{l}0,9994^{*} \\
(0,0870)\end{array}$ & $\begin{array}{l}0,9544^{* * *} \\
(0,0000)\end{array}$ & $\begin{array}{l}0,9995 \\
(0,1290)\end{array}$ & $\begin{array}{l}0,9546^{* * * *} \\
(0,0000)\end{array}$ & $\begin{array}{r}0,9993^{* *} \\
(0,0440)\end{array}$ \\
\hline metropolitana & $\begin{array}{l}0,8199^{\text {*** }} \\
(0,0000)\end{array}$ & $\begin{array}{l}0,9109^{* * *} \\
(0,0000)\end{array}$ & $\begin{array}{l}0,9492^{* * *} \\
(0,0000)\end{array}$ & $\begin{array}{l}0,9542^{* * *} \\
(0,0000)\end{array}$ & $\begin{array}{l}0,9708^{* * *} \\
(0,0000)\end{array}$ & $\begin{array}{l}0,9482^{\text {*** }} \\
(0,0000)\end{array}$ & $\begin{array}{l}1,2328^{* * *} \\
(0,0000)\end{array}$ & $\begin{array}{l}1,0348^{* * *} \\
(0,0000)\end{array}$ & $\begin{array}{l}1,0226^{* * *} \\
(0,0000)\end{array}$ & $\begin{array}{l}0,9734^{* * *} \\
(0,0000)\end{array}$ & $\begin{array}{l}1,0788^{* *} \\
(0,0000)\end{array}$ & $\begin{array}{l}0,9681^{\text {**** }} \\
(0,0000)\end{array}$ \\
\hline tx_esgot & & & $\begin{array}{l}0,8810^{* * * *} \\
(0,0000)\end{array}$ & $\begin{array}{l}0,8816^{* * * *} \\
(0,0000)\end{array}$ & $\begin{array}{l}1,2815^{* * *} \\
(0,0000)\end{array}$ & $\begin{array}{l}1,0213^{* * * *} \\
(0,0000)\end{array}$ & & & $\begin{array}{l}0,9501^{* * * *} \\
(0,0000)\end{array}$ & $\begin{array}{l}0,9812^{* * * *} \\
(0,0120)\end{array}$ & $\begin{array}{l}1,1400^{* * *} \\
(0,0000)\end{array}$ & $\begin{array}{l}1,0729^{* * *} \\
(0,0000)\end{array}$ \\
\hline med_anosest & & & $\begin{array}{l}0,8084^{* * * *} \\
(0,0000)\end{array}$ & $\begin{array}{l}0,9941 \\
(0,1500)\end{array}$ & $\begin{array}{l}0,8444^{* * *} \\
(0,0000)\end{array}$ & $\begin{array}{l}1,1013^{* * *} \\
(0,0000)\end{array}$ & & & $\begin{array}{l}1,0681^{* * * *} \\
(0,0000)\end{array}$ & $\begin{array}{l}0,7196^{* * *} \\
(0,0000)\end{array}$ & $\begin{array}{l}1,1231^{* * *} \\
(0,0000)\end{array}$ & $\begin{array}{l}0,8516^{* * *} \\
(0,0000)\end{array}$ \\
\hline grau_ind & & & $\begin{array}{l}0,8210^{* * *} \\
(0,0000)\end{array}$ & $\begin{array}{l}1,3765^{* * *} \\
(0,0000)\end{array}$ & $\begin{array}{l}0,6616^{* * * *} \\
(0,0000)\end{array}$ & $\begin{array}{l}1,2726^{* * *} \\
(0,0000)\end{array}$ & & & $\begin{array}{l}0,4144^{* * *} \\
(0,0000)\end{array}$ & $\begin{array}{l}0,2472^{* * *} \\
(0,0000)\end{array}$ & $\begin{array}{l}0,2274^{\text {**** }} \\
(0,0000)\end{array}$ & $\begin{array}{l}0,2216^{* * *} \\
(0,0000)\end{array}$ \\
\hline of_servmoder & & & $\begin{array}{l}0,4590^{* * *} \\
(0,0000)\end{array}$ & $\begin{array}{l}0,2272^{* * *} \\
(0,0000)\end{array}$ & $\begin{array}{l}0,5017^{* * * *} \\
(0,0000)\end{array}$ & $\begin{array}{l}0,2698^{* * *} \\
(0,0000)\end{array}$ & & & $\begin{array}{l}3,4998^{* * *} \\
(0,0000)\end{array}$ & $\begin{array}{l}0,5699^{* * * *} \\
(0,0000)\end{array}$ & $\begin{array}{l}2,1306^{* * *} \\
(0,0000)\end{array}$ & $\begin{array}{l}0,6641^{* * * *} \\
(0,0000)\end{array}$ \\
\hline $\mathrm{ft} \_q u a l i f$ & & & $\begin{array}{l}4,6691^{* * *} \\
(0,0000)\end{array}$ & $\begin{array}{l}0,5068^{* * *} \\
(0,0000)\end{array}$ & $\begin{array}{l}1,4825^{* * *} \\
(0,0000)\end{array}$ & $\begin{array}{l}0,1160^{* * *} \\
(0,0000)\end{array}$ & & & $\begin{array}{l}0,4919^{* * *} \\
(0,0000)\end{array}$ & $\begin{array}{l}6,1546^{* * *} \\
(0,0000)\end{array}$ & $\begin{array}{l}0,4677^{\text {****}} \\
(0,0000)\end{array}$ & $\begin{array}{l}5,0093^{* * *} \\
(0,0000)\end{array}$ \\
\hline tx_formal & & & $\begin{array}{l}0,1548^{* * *} \\
(0,0000)\end{array}$ & $\begin{array}{l}0,4901^{* * *} \\
(0,0000)\end{array}$ & $\begin{array}{l}0,1614^{* * *} \\
(0,0000)\end{array}$ & $\begin{array}{l}0,5467^{* * *} \\
(0,0000)\end{array}$ & & & $\begin{array}{l}1,9823^{* * *} \\
(0,0000)\end{array}$ & $\begin{array}{l}2,0520^{* * * *} \\
(0,0000)\end{array}$ & $\begin{array}{l}2,2014^{* * *} \\
(0,0000)\end{array}$ & $\begin{array}{l}2,3054^{* * * *} \\
(0,0000)\end{array}$ \\
\hline renddompc_medio & & & $\begin{array}{l}1,0003^{* * *} \\
(0,0000)\end{array}$ & $\begin{array}{l}1,0003^{* * *} \\
(0,0000)\end{array}$ & $\begin{array}{l}1,0004^{* * *} \\
(0,0000)\end{array}$ & $\begin{array}{l}1,0004^{* * *} \\
(0,0000)\end{array}$ & & & $\begin{array}{l}1,0002^{* * *} \\
(0,0000)\end{array}$ & $\begin{array}{l}0,9998^{* * *} \\
(0,0000)\end{array}$ & $\begin{array}{l}1,0000 \\
(0,5670)\end{array}$ & $\begin{array}{l}1,0000^{* * *} \\
(0,0060)\end{array}$ \\
\hline pobreza & & & $\begin{array}{l}0,1453^{* * *} \\
(0,0000)\end{array}$ & $\begin{array}{l}0,1172^{* * * *} \\
(0,0000)\end{array}$ & $\begin{array}{l}0,1389^{* * * *} \\
(0,0000)\end{array}$ & $\begin{array}{l}0,1080^{* * *} \\
(0,0000)\end{array}$ & & & $\begin{array}{l}1,3719^{* * *} \\
(0,0000)\end{array}$ & $\begin{array}{l}1,1617^{* * *} \\
(0,0000)\end{array}$ & $\begin{array}{l}2,3335^{* * *} \\
(0,0000)\end{array}$ & $\begin{array}{l}0,7924^{* * *} \\
(0,0000)\end{array}$ \\
\hline nordeste & & & & & $\begin{array}{l}0,9229^{* * *} \\
(0,0000)\end{array}$ & $\begin{array}{l}0,9894^{* * *} \\
(0,0000)\end{array}$ & & & & & $\begin{array}{l}0,7853^{* * *} \\
(0,0000)\end{array}$ & $\begin{array}{l}1,0198^{* * *} \\
(0,0000)\end{array}$ \\
\hline norte & & & & & $\bar{z}$ & $\bar{z}$ & & & & & - & $\overline{-}$ \\
\hline centro & & & & & $\begin{array}{l}1,0530^{* * * *} \\
(0,0000)\end{array}$ & $\begin{array}{l}1,0196^{* * *} \\
(0,0000)\end{array}$ & & & & & $\begin{array}{l}1,0751^{* * *} \\
(0,0000)\end{array}$ & $\begin{array}{l}0,8874^{* * *} \\
(0,0000)\end{array}$ \\
\hline sul & & & & & $\begin{array}{l}0,8620^{* * * *} \\
(0,0000)\end{array}$ & $\begin{array}{l}0,8134^{* * *} \\
(0,0000)\end{array}$ & & & & & $\begin{array}{l}0,9740^{\text {**** }} \\
(0,0000)\end{array}$ & $\begin{array}{l}0,6991^{* * *} \\
(0,0000)\end{array}$ \\
\hline sudeste & & & & & $\begin{array}{l}0,7163^{* * *} \\
(0,0000)\end{array}$ & $\begin{array}{l}0,8162^{* * *} \\
(0,0000)\end{array}$ & & & & & $\begin{array}{l}0,7790^{* * *} \\
(0,0000)\end{array}$ & $\begin{array}{l}0,7674^{* * *} \\
(0,0000)\end{array}$ \\
\hline $\mathrm{sp}$ & & & & & $\begin{array}{l}0,7150^{* * *} \\
(0,0000)\end{array}$ & $\begin{array}{l}0,8339^{* * *} \\
(0,0000)\end{array}$ & & & & & $\begin{array}{l}1,0183^{* *} \\
(0,0210)\end{array}$ & $\begin{array}{l}0,8030^{* * *} \\
(0,0000)\end{array}$ \\
\hline Pseudo-R2 & 0,1174 & 0,0982 & 0,1204 & 0,1029 & 0,1212 & 0,1032 & 0,1174 & 0,0982 & 0,1204 & 0,1029 & 0,1212 & 0,1032 \\
\hline
\end{tabular}

Fonte: elaboração própria a partir dos microdados dos Censos Demográficos 2000 e 2010.

$\left({ }^{* * *}\right)$ Variável significativa a $1 \% ;\left({ }^{* *}\right)$ Variável significativa a $\left.5 \% ;{ }^{*}\right)$ Variável significativa a $10 \%$.

A categoria de referência é igual a inativo (sitocup==0). Noobservações $2000=2751910$; nºbservações $2010=3171873$. 
Tabela 8: Probabilidades para as equações de inatividade, ocupação e desocupação dos homens (Brasil 2000-2010)

\begin{tabular}{|c|c|c|c|c|c|c|c|c|}
\hline \multicolumn{3}{|c|}{ Modelo 1A } & \multicolumn{3}{|c|}{$\begin{array}{c}2000 \\
\text { Modelo 2A }\end{array}$} & \multicolumn{3}{|c|}{ Modelo 3A } \\
\hline Inativo & Ativo e ocupado & Ativo e desocupado & Inativo & Ativo e ocupado & Ativo e desocupado & Inativo & Ativo e ocupado & Ativo e desocupado \\
\hline 0,0765 & 0,8512 & 0,0723 & 0,0762 & 0,8516 & 0,0722 & 0,0760 & 0,8521 & 0,0719 \\
\hline \multicolumn{9}{|c|}{2010} \\
\hline \multicolumn{3}{|c|}{ Modelo 1A } & \multicolumn{3}{|c|}{ Modelo 2A } & \multicolumn{3}{|c|}{ Modelo 3A } \\
\hline Inativo & Ativo e ocupado & Ativo e desocupado & Inativo & Ativo e ocupado & Ativo e desocupado & Inativo & Ativo e ocupado & Ativo e desocupado \\
\hline 0,0989 & 0,8717 & 0,0294 & 0,0983 & 0,8732 & 0,0285 & 0,0982 & 0,8734 & 0,0284 \\
\hline
\end{tabular}

Fonte: elaboração própria a partir dos microdados dos Censos Demográficos 2000 e 2010.

A categoria de referência é igual a inativo ( sitocup $==0$ ). 
demais indicadores da densidade urbana, conforme descrito anteriormente. Ou seja, em 2010, o elevado grau de competição dos mercados de trabalho dos grandes centros urbanos metropolitanos minimiza eventuais aumentos de probabilidade de ocupação que poderiam se estimulados pelo desenvolvimento de atividades intensivas em conhecimento nas microrregiões brasileiras (o aumento do emprego nesse setor não necessariamente implica aumento da probabilidade de obtenção de emprego devido aos expressivos níveis de qualificação e treinamento que essas ocupações exigem).

Observa-se que as estimações para o grau de industrialização corroboram esses resultados para 2000, todavia, em 2010, a residência em uma microrregião com elevado grau de industrialização volta a contribuir para o aumento da probabilidade de ocupação individual (aproximadamente 37\%), o que provavelmente está relacionado à recuperação do crescimento do emprego nesse setor, conforme evidenciam dados da Pesquisa Industrial Mensal de Emprego e Salário do IBGE. Em outras palavras, as estimações para a variável grau_ind parecem refletir que a importância desse setor para a inserção ocupacional dos trabalhadores brasileiros continua a ser expressiva, especialmente em seus momentos de expansão. Salienta-se ainda, que a contribuição da renda domiciliar per capita média para a obtenção de emprego é positiva, mas pouco expressiva. Por fim, o indicador de pobreza evidencia que em regiões estagnadas é mais difícil obter trabalho, muito provavelmente pela falta de dinamismo local (escassez de empregos).

A estimação do modelo completo (modelo 3A) evidencia que indivíduos residentes na região Centro-Oeste possuem probabilidade de ocupação ligeiramente superior a dos residentes em outras macrorregiões do país $(5 \% \mathrm{em}$ 2000 e $2 \%$ em 2010). As demais variáveis indicadoras das macrorregiões (nordeste, sul, sudeste e São Paulo) apresentam razões de riscos relativos menores do que um, indicando maior dificuldade de inserção ocupacional para indivíduos residentes nas mesmas em comparação a não residentes ${ }^{3}$. As odds ratio das regiões sudeste, sul e de São Paulo são as menos expressivas, indicando, provavelmente, a dificuldade de obter emprego em áreas de intenso dinamismo (elevada competição por postos de trabalho). Vale salientar que nesse modelo, a única alteração das razões de riscos relativos em comparação aos modelos anteriores ( $1 \mathrm{~B}$ e $2 \mathrm{~B}$ ) ocorre para a variável taxa de esgotamento sanitário. Ou seja, ao inserir as variáveis indicadoras das macrorregiões de residência no modelo fica evidente o trade off existente no processo de decisão ocupacional dos trabalhadores residentes em grandes áreas urbanas metropolitanas: por um lado, a expressiva escala urbana pode contribuir para a obtenção de emprego devido à capacidade local de gerar novos postos de trabalho; por outro lado, a complexidade dos mercados de trabalhos urbanos, que exigem elevados níveis de qualificação e treinamento da mão de obra, e a expressiva competição pelos postos de trabalho dificultam a inserção ocupacional dos indivíduos.

Ao comparar a categoria ativo e desocupado com a alternativa de inatividade, percebe-se que a probabilidade de desocupação aumenta, principalmente, com a probabilidade de migração individual e com a idade. Um aumento percentual na probabilidade de ser migrante eleva em aproximadamente $26 \%$ a probabilidade de desocupação individual em 2000 e $19 \%$ em

\footnotetext{
${ }^{3}$ A variável "norte" não foi incluída na análise, pois devido às suas características produtivas (voltadas principalmente para atividades agrícolas) foi escolhida para se a baseline regional.
} 
2010; para indivíduos mais velhos, esse aumento é de $20 \%$ nos dois anos analisados. As explicações para essas probabilidades residem, provavelmente, na dificuldade de adaptação dos migrantes aos novos contextos sociais e a incapacidade dos mercados de trabalho em absorver indivíduos mais velhos, especialmente os idosos, devido ao seu elevado custo de treinamento (possuem vícios trabalhistas que dificilmente são revertidos). Pessoas com maiores níveis de escolaridade possuem uma probabilidade de desocupação ligeiramente inferior a dos não escolarizados, provavelmente porque esses indivíduos são mais competitivos nos mercados de trabalho. Indivíduos que residiam em áreas metropolitanas em 2000 possuíam maior probabilidade de desocupação, situação que não é mais observada em 2010, principalmente quando são incorporadas variáveis regionais aos modelos. Muito provavelmente, a dificuldade de obtenção de trabalho nas grandes regiões metropolitanas brasileiras (altamente competitivas) pode ter estimulado a saída de alguns indivíduos da população economicamente ativa (desalento no mercado de trabalho). Ou seja, as razões de riscos relativos da variável "metropolitana" nos modelos que incorporam as características regionais retratam a dificuldade de obter emprego nos grandes centros urbanos brasileiros devido à elevada oferta de mão de obra e aos níveis de exigência dos empregadores. O desalento também pode ser utilizado para explicar porque a probabilidade de desocupação dos indivíduos responsáveis pelo domicílio caiu entre 2000 e 2010 em comparação aos demais indivíduos.

Nessa comparação (desocupados versus inativos), os indicadores regionais possuem impactos bastante diversificados. As razões de riscos relativos da taxa de esgotamento sanitário ( proxy para infraestrutura urbana) evidenciam que indivíduos residentes em microrregiões com níveis mais elevados de urbanização tendem a possuir menor probabilidade de desocupação (modelo $2 \mathrm{~A}$ ) - preferem a inatividade devido às dificuldades de obtenção de emprego nos grandes centros urbanos metropolitanos. Contudo, ao inserir na análise as variáveis indicadoras das macrorregiões de residência (modelo 3A), essas odds ratio tornam-se maiores do que 01 , destacando que, dadas as particularidades macrorregionais, a escala urbana tende a estimular a permanência individual na população economicamente ativa, ainda que o sucesso (inserção) não seja obtido no curto prazo. A residência em microrregiões com elevados níveis médios de escolaridade e expressiva oferta de serviços modernos aumentava a probabilidade de desocupação em 2000, oposto do resultado obtido para 2010. Essa mudança provavelmente é justificada pelo desalento dos trabalhadores urbanos ao longo do período analisado: o elevado nível de exigência dos mercados de trabalho das regiões caracterizadas por alta escolaridade e atividades intensivas em conhecimento/tecnologia dificulta a inserção ocupacional dos indivíduos, estimulando assim a saída dos mesmos da população economicamente ativa (trade off entre desocupação e inatividade). Relação similar é observada para a variável força de trabalho qualificada, porém, invertendo os valores das odds ratio para cada ano analisado. Esse resultado (presença de força de trabalho qualificada passa a estimular a permanência na população economicamente ativa, ainda que o indivíduo não obtenha emprego) pode estar relacionado ao aumento geral dos níveis médios de escolaridade observados na economia brasileira ao longo dos últimos anos (expectativa de que o aumento individual da escolaridade poderá facilitar a inserção nos mercados de trabalho, que valorizam a educação formal).

O nível de formalização dos mercados de trabalho funciona durante todo 
o período analisado como um fator de estímulo à permanência no grupo populacional economicamente ativo. Muito provavelmente, as expectativas de condições de trabalho e emprego mais favoráveis em microrregiões com elevadas taxas de formalização têm estimulado a continuidade da busca por um novo posto de trabalho, aumentando, assim, a probabilidade de desocupação em comparação à inatividade. A forte presença do setor industrial, por sua vez, diminui a probabilidade de desocupação durante todo o período analisado. Ou seja, indivíduos residentes em microrregiões com elevados níveis de industrialização possuem menor probabilidade de ficar sem trabalho quando comparados a indivíduos residentes em regiões com indicadores menos expressivos, pois as primeiras regiões provavelmente possuem maiores oportunidades de emprego.

Assim como é observado para a probabilidade de ocupação, a contribuição da renda domiciliar per capita média para desocupação é positiva, mas pouco expressiva. Por fim, o indicador de pobreza evidencia que em regiões estagnadas é mais difícil obter trabalho devido ao baixo dinamismo local, o que aumenta a probabilidade de desocupação (exceto para o modelo completo em 2010, ou seja, mais recentemente, indivíduos residentes em localidades com elevadas taxas de pobreza e de desemprego têm optado pela inatividade).

A influência da localização macrorregional sobre a probabilidade de estar desocupado em comparação à inatividade é relativamente homogênea, mas as chances de estar desempregado em 2010 são maiores na região Nordeste. Ressalta-se que em 2000, a residência nessa região refletia-se em menor probabilidade de desocupação (maior inatividade). Essa alteração nas odds ratio da região pode ser explicada pelo aumento da competitividade nos mercados de trabalho locais nos anos mais recentes, estimulada inclusive pela migração de retorno. Salienta-se também que a probabilidade de desocupação na região Centro-Oeste e no estado de São Paulo eram mais elevadas em 2000 (7,5\% e 1,8\%, respectivamente), situação oposta à vigente em 2010 .

De forma geral, os resultados dos modelos para a categoria ativo e desocupado indicam que os indivíduos brancos, responsáveis pelo domicílio, com maior nível educacional, residentes em microrregiões com elevados níveis de escolaridade e de industrialização possuem menores chances de permanecer fora dos mercados de trabalho. Essa probabilidade é ainda menor se a microrregião de residência estiver localizada na região Sul do país. Em contrapartida, indivíduos que residem em microrregiões com elevadas taxas de qualificação da mão de obra e formalização possuem, maior probabilidade de desocupação.

As informações da tabela 7 também evidenciam que os indivíduos negros, não responsáveis pelo domicílio, com menor escolaridade, residentes em áreas metropolitanas e com elevadas taxas de diversificação produtiva possuem maior probabilidade de inatividade, pois a inadequação dos mesmos aos requerimentos dos mercados de trabalho funciona como um estímulo à sua saída dos setores produtivos (os indivíduos optam por não desempenhar funções econômicas).

Por fim, as probabilidades médias de ocupação, desocupação e inatividade do sexo masculino podem ser observadas na tabela 8 . Não há variabilidade significativa dessas probabilidades entre os modelos estimados, contudo, ao inserir as características microrregionais nota-se um pequeno aumento nas chances de obter um emprego. De modo geral, os homens brasileiros residentes em áreas urbanas possuem uma elevada probabilidade de ocupação (entre 
0,85 e 0,87), especialmente quando comparados às mulheres, o que poderá ser comprovado a partir da análise dos modelos estimados para este grupo.

\section{A escolha ocupacional feminina}

As mulheres possuem características não produtivas significativamente diferentes dos homens, o que afeta seu ingresso e permanência nos mercados de trabalho, bem como sua respectiva remuneração. Essas diferenças evidenciam a importância de separar esses grupos para tornar a análise dos determinantes da escolha ocupacional mais homogênea. Os resultados gerais dos modelos estimados para as mulheres evidenciam a influência dessas diferenças sobre a escolha ocupacional feminina. Os dados expostos na tabela 09 demonstram que a probabilidade média de uma mulher estar ocupada é significativamente inferior àquela observada para os homens $(0,50$ versus 0,85 em 2000 e 0,61 versus 0,87 em 2010, respectivamente). A probabilidade de inatividade feminina era aproximadamente cinco vezes mais elevada que a masculina em 2000 e o triplo da masculina em 2010. Essa elevada inatividade está relacionada principalmente ao trade off que as mulheres continuam a enfrentar entre desempenhar atividades produtivas ou dedicar-se a tarefas não produtivas, como a administração do lar, apesar das melhorias obtidas no período analisado.

Assim como na análise masculina, a categoria de referência é inativo, logo, a interpretação dos resultados dos modelos considera a probabilidade de uma mulher estar ocupada (ou desocupada) em detrimento da inatividade. Os resultados da estimação dos modelos multinomiais estão descritos na tabela 10 .

As estimativas dos modelos para as mulheres mantêm, de forma geral, as mesmas características dos modelos para os homens. No caso da alternativa ativa e ocupada, as principais diferenças provavelmente referem-se ao aumento da probabilidade de conseguir um emprego em comparação à inatividade para mulheres brancas no final do período e à incapacidade da migração aumentar essa probabilidade. A não contribuição da migração para a obtenção de uma ocupação pode estar relacionada ao fato de a migração feminina ser majoritariamente de acompanhamento familiar, todavia, os dados analisados neste artigo são insuficientes para realizar essa afirmação. Mulheres mais velhas possuem chances mais elevadas de ter um emprego (a probabilidade é aproximadamente $6 \%$ maior do que a observada para mulheres mais jovens em 2000 e 13\% em 2010), assim como aquelas que são responsáveis pelos seus respectivos domicílios (aproximadamente $90 \%$ em 2000 e $40 \%$ em 2010) e que possuem maiores níveis de escolaridade (entre 15\% e 16\% em todo o período analisado).

Mulheres que residiam em microrregiões com elevados níveis de escolaridade média possuíam maior dificuldade de inserção ocupacional em 2000, todavia, em 2010 a residência nessas localidades gera para as mesmas uma probabilidade de ocupação $17 \%$ mais elevada em comparação às mulheres que residem em áreas de baixo nível educacional (modelo completo 3B). A moradia em microrregiões industrializadas aumenta essa probabilidade significativamente, provavelmente porque há maiores oportunidades de trabalho geradas pelas intensas relações setoriais dessas atividades, com expressiva incorporação da mão de obra feminina nos últimos anos. Regiões com elevados níveis médios de rendimento domiciliar per capita também favorecem suas moradoras em comparação às residentes em áreas estagnadas, mas de forma bastante sutil (odds ratio próximas à unidade); o oposto ocorre em microrre- 
Tabela 9: Razão de riscos relativos de regressão logística multinomial para a condição de ocupação individual mulheres (Brasil, 2000-10)

\begin{tabular}{|c|c|c|c|c|c|c|c|c|c|c|c|c|}
\hline \multirow[b]{3}{*}{ branco } & \multicolumn{6}{|c|}{ Categoria 1 = ativo e ocupado } & \multicolumn{6}{|c|}{ Categoria 2 = ativo e desocupado } \\
\hline & \multicolumn{2}{|c|}{ Modelo 1B } & \multicolumn{2}{|c|}{ Modelo 2B } & \multicolumn{2}{|c|}{ Modelo 3B } & \multicolumn{2}{|c|}{ Modelo 1B } & \multicolumn{2}{|c|}{ Modelo 2B } & \multicolumn{2}{|c|}{ Modelo 3B } \\
\hline & $\begin{array}{l}0,9726^{* * *} \\
(0,0000)\end{array}$ & $\begin{array}{l}1,1435^{\text {*** }} \\
(0,0000)\end{array}$ & $\begin{array}{l}0,8956^{\text {*** }} \\
(0,0000)\end{array}$ & $\begin{array}{l}1,0131^{* * *} \\
(0,0000)\end{array}$ & $\begin{array}{l}0,8806^{* * *} \\
(0,0000)\end{array}$ & $\begin{array}{l}1,0059^{* * * *} \\
(0,0000)\end{array}$ & $\begin{array}{l}0,8108^{* * *} \\
(0,0000)\end{array}$ & $\begin{array}{l}0,8425^{\text {*** }} \\
(0,0000)\end{array}$ & $\begin{array}{l}0,7789^{* * * *} \\
(0,0000)\end{array}$ & $\begin{array}{l}0,8452^{* * *} \\
(0,0000)\end{array}$ & $\begin{array}{l}0,7676^{\text {*** }} \\
(0,0000)\end{array}$ & $\begin{array}{l}0,8412^{* * * *} \\
(0,0000)\end{array}$ \\
\hline idade & $\begin{array}{l}1,0622^{* * *} \\
(0,0000)\end{array}$ & $\begin{array}{l}1,1325^{* * *} \\
(0,0000)\end{array}$ & $\begin{array}{l}1,0583^{* * *} \\
(0,0000)\end{array}$ & $\begin{array}{l}1,1275^{* * *} \\
(0,0000)\end{array}$ & $\begin{array}{l}1,0583^{* * *} \\
(0,0000)\end{array}$ & $\begin{array}{l}1,1276^{* * *} \\
(0,0000)\end{array}$ & $\begin{array}{l}0,9716^{* * *} \\
(0,0000)\end{array}$ & $\begin{array}{l}1,0074^{* * *} \\
(0,0000)\end{array}$ & $\begin{array}{l}0,9694^{* * *} \\
(0,0000)\end{array}$ & $\begin{array}{l}1,0073^{* * *} \\
(0,0000)\end{array}$ & $\begin{array}{l}0,9692^{* * *} \\
(0,0000)\end{array}$ & $\begin{array}{l}1,0074^{* * *} \\
(0,0000)\end{array}$ \\
\hline idade2 & $\begin{array}{l}0,9980^{* * * *} \\
(0,0000)\end{array}$ & $\begin{array}{l}0,9978^{* * *} \\
(0,0000)\end{array}$ & $\begin{array}{l}0,9981^{* * *} \\
(0,0000)\end{array}$ & $\begin{array}{l}0,9979^{* * * *} \\
(0,0000)\end{array}$ & $\begin{array}{l}0,9981^{* * *} \\
(0,0000)\end{array}$ & $\begin{array}{l}0,9979^{* * * *} \\
(0,0000)\end{array}$ & $\begin{array}{l}0,9987^{* * *} \\
(0,0000)\end{array}$ & $\begin{array}{l}0,9985^{* * * *} \\
(0,0000)\end{array}$ & $\begin{array}{l}0,9987^{* * *} \\
(0,0000)\end{array}$ & $\begin{array}{l}0,9985^{* * *} \\
(0,0000)\end{array}$ & $\begin{array}{l}0,9987^{* * *} \\
(0,0000)\end{array}$ & $\begin{array}{l}0,9985^{* * * *} \\
(0,0000)\end{array}$ \\
\hline respdom & $\begin{array}{l}1,9299^{* * *} \\
(0,0000)\end{array}$ & $\begin{array}{l}1,4013^{* * *} \\
(0,0000)\end{array}$ & $\begin{array}{l}1,9460^{* * *} \\
(0,0000)\end{array}$ & $\begin{array}{l}1,4143^{* * *} \\
(0,0000)\end{array}$ & $\begin{array}{l}1,9460^{* * *} \\
(0,0000)\end{array}$ & $\begin{array}{l}1,4130^{* * *} \\
(0,0000)\end{array}$ & $\begin{array}{l}1,4360^{* * *} \\
(0,0000)\end{array}$ & $\begin{array}{l}1,2352^{\text {**** }} \\
(0,0000)\end{array}$ & $\begin{array}{l}1,4355^{\text {**** }} \\
(0,0000)\end{array}$ & $\begin{array}{l}1,2446^{* * *} \\
(0,0000)\end{array}$ & $\begin{array}{l}1,4364^{\text {*** }} \\
(0,0000)\end{array}$ & $\begin{array}{l}1,2442^{* * *} \\
(0,0000)\end{array}$ \\
\hline pmigrante & $\begin{array}{l}0,7545^{* * *} \\
(0,0000)\end{array}$ & $\begin{array}{l}0,8688^{* * *} \\
(0,0000)\end{array}$ & $\begin{array}{l}0,7508^{* * *} \\
(0,0000)\end{array}$ & $\begin{array}{l}0,8632^{* * *} \\
(0,0000)\end{array}$ & $\begin{array}{l}0,7507^{* * *} \\
(0,0000)\end{array}$ & $\begin{array}{l}0,8632^{* * *} \\
(0,0000)\end{array}$ & $\begin{array}{l}0,7379^{* * *} \\
(0,0000)\end{array}$ & $\begin{array}{l}0,8014^{* * *} \\
(0,0000)\end{array}$ & $\begin{array}{l}0,7371^{* * *} \\
(0,0000)\end{array}$ & $\begin{array}{l}0,8042^{* * *} \\
(0,0000)\end{array}$ & $\begin{array}{l}0,7367^{* * *} \\
(0,0000)\end{array}$ & $\begin{array}{l}0,8042^{* * * *} \\
(0,0000)\end{array}$ \\
\hline anosest & $\begin{array}{l}1,1630^{* * * *} \\
(0,0000)\end{array}$ & $\begin{array}{l}1,1500^{* * *} \\
(0,0000)\end{array}$ & $\begin{array}{l}1,1655^{* * *} \\
(0,0000)\end{array}$ & $\begin{array}{l}1,1519^{* * * *} \\
(0,0000)\end{array}$ & $\begin{array}{l}1,1659^{* * *} \\
(0,0000)\end{array}$ & $\begin{array}{l}1,1520^{* * *} \\
(0,0000)\end{array}$ & $\begin{array}{l}1,0636^{* * *} \\
(0,0000)\end{array}$ & $\begin{array}{l}1,0867^{* * *} \\
(0,0000)\end{array}$ & $\begin{array}{l}1,0606^{* * *} \\
(0,0000)\end{array}$ & $\begin{array}{l}1,0834^{* * *} \\
(0,0000)\end{array}$ & $\begin{array}{l}1,0609^{* * *} \\
(0,0000)\end{array}$ & $\begin{array}{l}1,0834^{* * *} \\
(0,0000)\end{array}$ \\
\hline metropolitana & $\begin{array}{l}0,9334^{* * *} \\
(0,0000)\end{array}$ & $\begin{array}{l}1,0121^{* * *} \\
(0,0000)\end{array}$ & $\begin{array}{l}0,9896^{* * *} \\
(0,0000)\end{array}$ & $\begin{array}{l}1,0272^{* * *} \\
(0,0000)\end{array}$ & $\begin{array}{r}1,0036^{* *} \\
(0,0220)\end{array}$ & $\begin{array}{l}1,0087^{* * *} \\
(0,0000)\end{array}$ & $\begin{array}{l}1,2999^{* * *} \\
(0,0000)\end{array}$ & $\begin{array}{l}1,1778^{* * *} \\
(0,0000)\end{array}$ & $\begin{array}{r}1,0057^{* *} \\
(0,0230)\end{array}$ & $\begin{array}{l}1,0274^{* * *} \\
(0,0000)\end{array}$ & $\begin{array}{l}1,0500^{* * *} \\
(0,0000)\end{array}$ & $\begin{array}{l}1,0394^{* * *} \\
(0,0000)\end{array}$ \\
\hline tx_esgot & & & $\begin{array}{l}0,8735^{* * *} \\
(0,0000)\end{array}$ & $\begin{array}{l}0,9562^{* * *} \\
(0,0000)\end{array}$ & $\begin{array}{l}1,1613^{* * * *} \\
(0,0000)\end{array}$ & $\begin{array}{l}1,0724^{* * *} \\
(0,0000)\end{array}$ & & & $\begin{array}{c}1,0002 \\
(0,9560)\end{array}$ & $\begin{array}{l}1,2377^{* * *} \\
(0,0000)\end{array}$ & $\begin{array}{l}1,0804^{* * * *} \\
(0,0000)\end{array}$ & $\begin{array}{l}1,2936^{* * *} \\
(0,0000)\end{array}$ \\
\hline med_anosest & & & $\begin{array}{l}0,9065^{\text {**** }} \\
(0,0000)\end{array}$ & $\begin{array}{l}1,1320^{* * *} \\
(0,0000)\end{array}$ & $\begin{array}{l}0,9293^{* * *} \\
(0,0000)\end{array}$ & $\begin{array}{l}1,1788^{* * *} \\
(0,0000)\end{array}$ & & & $\begin{array}{l}1,1348^{* * * *} \\
(0,0000)\end{array}$ & $\begin{array}{l}0,8712^{* * *} \\
(0,0000)\end{array}$ & $\begin{array}{l}1,1802^{* * *} \\
(0,0000)\end{array}$ & $\begin{array}{l}0,9309^{* * * *} \\
(0,0000)\end{array}$ \\
\hline grau_ind & & & $\begin{array}{l}1,4365^{\text {*** }} \\
(0,0000)\end{array}$ & $\begin{array}{l}2,7600^{* * *} \\
(0,0000)\end{array}$ & $\begin{array}{l}1,0224^{*} \\
(0,0720)\end{array}$ & $\begin{array}{l}2,2647^{* * *} \\
(0,0000)\end{array}$ & & & $\begin{array}{l}0,5265^{\text {**** }} \\
(0,0000)\end{array}$ & $\begin{array}{l}0,2714^{* * *} \\
(0,0000)\end{array}$ & $\begin{array}{l}0,2539^{\text {*** }} \\
(0,0000)\end{array}$ & $\begin{array}{l}0,1893^{* * *} \\
(0,0000)\end{array}$ \\
\hline of_servmoder & & & $\begin{array}{l}1,1803^{* * *} \\
(0,0000)\end{array}$ & $\begin{array}{l}1,0434 \\
(0,1380)\end{array}$ & $\begin{array}{l}0,5416^{* * *} \\
(0,0000)\end{array}$ & $\begin{array}{l}0,9476^{*} \\
(0,0750)\end{array}$ & & & $\begin{array}{l}7,3273^{* * *} \\
(0,0000)\end{array}$ & $\begin{array}{l}0,7580^{* * *} \\
(0,0000)\end{array}$ & $\begin{array}{l}2,4104^{* * *} \\
(0,0000)\end{array}$ & $\begin{array}{l}0,4492^{* * *} \\
(0,0000)\end{array}$ \\
\hline $\mathrm{ft}$ qualif & & & $\begin{array}{l}1,4594^{* * *} \\
(0,0000)\end{array}$ & $\begin{array}{l}0,0945^{* * *} \\
(0,0000)\end{array}$ & $\begin{array}{l}0,7245^{* * * *} \\
(0,0000)\end{array}$ & $\begin{array}{l}0,0665^{* * *} \\
(0,0000)\end{array}$ & & & $\begin{array}{l}0,3256^{* * * *} \\
(0,0000)\end{array}$ & $\begin{array}{l}9,0362^{* * *} \\
(0,0000)\end{array}$ & $\begin{array}{l}0,2931^{* * *} \\
(0,0000)\end{array}$ & $\begin{array}{l}3,4461^{* * *} \\
(0,0000)\end{array}$ \\
\hline tx_formal & & & $\begin{array}{l}0,3480^{\text {**** }} \\
(0,0000)\end{array}$ & $\begin{array}{l}0,4831^{* * *} \\
(0,0000)\end{array}$ & $\begin{array}{l}0,3068^{* * *} \\
(0,0000)\end{array}$ & $\begin{array}{l}0,4771^{* * *} \\
(0,0000)\end{array}$ & & & $\begin{array}{l}2,7703^{* * *} \\
(0,0000)\end{array}$ & $\begin{array}{l}1,3020^{* * *} \\
(0,0000)\end{array}$ & $\begin{array}{l}2,7346^{* * *} \\
(0,0000)\end{array}$ & $\begin{array}{l}1,2766^{* * *} \\
(0,0000)\end{array}$ \\
\hline renddompc_medio & & & $\begin{array}{l}0,9999^{* * *} \\
(0,0000)\end{array}$ & $\begin{array}{l}1,0004^{* * *} \\
(0,0000)\end{array}$ & $\begin{array}{l}1,0002^{* * *} \\
(0,0000)\end{array}$ & $\begin{array}{l}1,0004^{* * *} \\
(0,0000)\end{array}$ & & & $\begin{array}{l}0,9997^{* * * *} \\
(0,0000)\end{array}$ & $\begin{array}{l}0,9998^{* * *} \\
(0,0000)\end{array}$ & $\begin{array}{l}0,9997^{* * * *} \\
(0,0000)\end{array}$ & $\begin{array}{l}0,9998^{* * *} \\
(0,0000)\end{array}$ \\
\hline pobreza & & & $\begin{array}{l}0,1875^{\text {*** }} \\
(0,0000)\end{array}$ & $\begin{array}{l}0,1888^{* * *} \\
(0,0000)\end{array}$ & $\begin{array}{l}0,1649^{* * *} \\
(0,0000)\end{array}$ & $\begin{array}{l}0,2039^{* * *} \\
(0,0000)\end{array}$ & & & $\begin{array}{l}1,0643^{\text {**** }} \\
(0,0040)\end{array}$ & $\begin{array}{l}0,4400^{* * *} \\
(0,0000)\end{array}$ & $\begin{array}{l}1,4260^{\text {****}} \\
(0,0000)\end{array}$ & $\begin{array}{l}0,3424^{* * *} \\
(0,0000)\end{array}$ \\
\hline nordeste & & & & & $\begin{array}{l}1,1408^{* * *} \\
(0,0000)\end{array}$ & $\begin{array}{l}1,0522^{* * *} \\
(0,0000)\end{array}$ & & & & & $\begin{array}{l}0,9083^{\text {****}} \\
(0,0000)\end{array}$ & $\begin{array}{l}1,0104^{* *} \\
(0,0120)\end{array}$ \\
\hline norte & & & & & $\bar{z}$ & $=$ & & & & & - & $=$ \\
\hline centro & & & & & $\begin{array}{l}0,9582^{* * *} \\
(0,0000)\end{array}$ & $\begin{array}{l}1,0322^{* * *} \\
(0,0000)\end{array}$ & & & & & $\begin{array}{l}0,8798^{* * *} \\
(0,0000)\end{array}$ & $\begin{array}{l}0,8767^{* * * *} \\
(0,0000)\end{array}$ \\
\hline sul & & & & & $\begin{array}{l}1,1579^{* * * *} \\
(0,0000)\end{array}$ & $\begin{array}{l}1,0860^{* * * *} \\
(0,0000)\end{array}$ & & & & & $\begin{array}{l}1,1043^{* * * *} \\
(0,0000)\end{array}$ & $\begin{array}{l}0,9416^{* * * *} \\
(0,0000)\end{array}$ \\
\hline sudeste & & & & & $\begin{array}{l}0,9329^{* * *} \\
(0,0000)\end{array}$ & $\begin{array}{l}0,9628^{* * *} \\
(0,0000)\end{array}$ & & & & & $\begin{array}{l}0,9044^{\text {*** }} \\
(0,0000)\end{array}$ & $\begin{array}{l}0,8915^{* * *} \\
(0,0000)\end{array}$ \\
\hline $\mathrm{sp}$ & & & & & $\begin{array}{l}0,8901^{* * *} \\
(0,0000)\end{array}$ & $\begin{array}{l}0,9862^{* * *} \\
(0,0000)\end{array}$ & & & & & $\begin{array}{l}1,1086^{* * *} \\
(0,0000)\end{array}$ & $\begin{array}{l}0,9821^{* * *} \\
(0,0010)\end{array}$ \\
\hline Pseudo-R2 & 0,0958 & 0,0829 & 0,0984 & 0,0886 & 0,0991 & 0,0887 & 0,0958 & 0,0829 & 0,0984 & 0,0886 & 0,0991 & 0,0887 \\
\hline
\end{tabular}

Fonte: elaboração própria a partir dos microdados dos Censos Demográficos 2000 e 2010.

$\left({ }^{* * *}\right)$ Variável significativa a $1 \% ;\left(^{* *}\right)$ Variável significativa a $5 \% ;\left(^{*}\right)$ Variável significativa a $10 \%$.

A categoria de referência é igual a inativo (sitocup= $=0$ ). $\mathrm{N}^{\circ}$ observações $2000=2920021 ; \mathrm{n}^{\circ}$ observações $2010=3415178$. 
Tabela 10: Probabilidades para as equações de inatividade, ocupação e desocupação das mulheres (Brasil 2000-2010)

\begin{tabular}{|c|c|c|c|c|c|c|c|c|}
\hline \multicolumn{3}{|c|}{ Modelo 1B } & \multicolumn{3}{|c|}{$\begin{array}{c}2000 \\
\text { Modelo 2B }\end{array}$} & \multicolumn{3}{|c|}{ Modelo 3B } \\
\hline Inativo & Ativo e ocupado & Ativo e desocupado & Inativo & Ativo e ocupado & Ativo e desocupado & Inativo & Ativo e ocupado & Ativo e desocupado \\
\hline 0,4139 & 0,4992 & 0,0869 & 0,4142 & 0,4994 & 0,0864 & 0,4142 & 0,4996 & 0,0862 \\
\hline \multicolumn{9}{|c|}{2010} \\
\hline \multicolumn{3}{|c|}{ Modelo 1B } & \multicolumn{3}{|c|}{ Modelo 2B } & \multicolumn{3}{|c|}{ Modelo 3B } \\
\hline Inativo & Ativo e ocupado & Ativo e desocupado & Inativo & Ativo e ocupado & Ativo e desocupado & Inativo & Ativo e ocupado & Ativo e desocupado \\
\hline 0,3428 & 0,6121 & 0,0451 & 0,3423 & 0,6132 & 0,0445 & 0,3424 & 0,6131 & 0,0445 \\
\hline
\end{tabular}

Fonte: elaboração própria a partir dos microdados dos Censos Demográficos 2000 e 2010.

A categoria de referência é igual a inativo (sitocup $==0$ ). 
giões com elevadas taxas de pobreza. As razões de riscos relativos das variáveis regionais indicadoras das estruturas trabalhistas (proporção de mão de obra qualificada e taxa de formalização) evidenciam a dificuldade de inserção ocupacional em mercados dinâmicos e sofisticados, pois residir em regiões com elevados valores dessas variáveis reduz as chances de obter um trabalho. É interessante observar que a contribuição da variável indicadora da densidade urbana - oferta de serviços modernos - varia significativamente entre os modelos $2 \mathrm{~B}$ e $3 \mathrm{~B}$, evidenciando que a incorporação das particularidades macrorregionais na análise (dummies regionais) tende a corroborar a complexidade inerente aos mercados de trabalho dos grandes centros urbanos metropolitanos (maior concorrência pelos postos de trabalho, que exigem níveis mais elevados de treinamento e qualificação da mão de obra). Simultaneamente, as estimações demonstram que as chances de ocupação feminina em áreas metropolitanas tendem a ser ligeiramente mais elevadas em comparação à probabilidade ocupacional de mulheres residentes em áreas não metropolitanas nos anos mais recentes, um provável reflexo da maior capacidade de diversificação dos mercados de trabalho metropolitanos.As dummies regionais indicam que o ingresso feminino no mercado de trabalho é mais fácil nas regiões Sul e Nordeste do Brasil e mais recentemente na região Centro-Oeste.

Essas tendências evidenciam que a residência em microrregiões com maiores rendimentos, grau de industrialização e média de anos de estudo aumenta a probabilidade de ocupação feminina; a residência em microrregiões com elevadas taxas de formalização, mão de obra qualificada e pobreza diminui essa probabilidade por motivos diametralmente opostos. O aumento da escolaridade e a emancipação feminina (leia-se chefia do domicílio) são as formas mais factíveis de aumentar sua probabilidade de ocupação. A efetivação da migração reduz essa probabilidade.

Por fim, os fatores que determinam a escolha pela atividade e desocupação em detrimento da inatividade estão relacionados principalmente à chefia domiciliar, elevada escolaridade, residência em áreas metropolitanas (odds ratio das variáveis metropolitana e taxa de esgoto são maiores do que $01 \mathrm{em}$ todos os modelos estimados) e a elevadas taxas de formalização. Mulheres que apresentam essas características tendem a elevar suas chances de desocupação em relação aos seus respectivos grupos (chefes de domicílios versus não chefes, residentes em áreas metropolitanas versus não residentes, etc.), pois preferem exercer algum tipo de atividade produtiva, mesmo que o custo de oportunidade de permanecer temporariamente fora do mercado de trabalho seja significativo. Por exemplo, as mulheres mais escolarizadas possuem chances entre $6 \%$ e $8 \%$ mais elevadas de estarem desocupadas quando comparadas às demais. Mulheres chefes do domicílio também possuem maior probabilidade de desocupação ( aproximadamente $43 \%$ mais elevada em 2000 e $24 \%$ em 2010), pois tendem a se manter ativas mesmo em condições desfavoráveis devido à necessidade de prover seus respectivos domicílios.

É interessante observar que quanto mais elevada a probabilidade de uma mulher ser migrante, maior a probabilidade de inatividade da mesma. Esse resultado, assim como o obtido para a categoria 01 (ocupação), provavelmente está relacionado à importância da migração familiar para a efetivação do deslocamento feminino no país. Sob a hipótese do deslocamento ter sido realizado para acompanhar o cônjuge, a probabilidade de atividade feminina diminui, uma vez que a busca por novos postos de trabalho e emprego é limitada pela necessidade de desempenhar atividades não diretamente relacionadas à 
dinâmica dos mercados de trabalho brasileiros.

As características microrregionais que reforçam a escolha pela busca de trabalho ao invés da inatividade são basicamente as mesmas observadas para os homens. De forma geral, mulheres que residem em regiões mais urbanizadas aumentam em $29 \%$ as chances de desocupação quando comparadas às não residentes; se essas regiões possuem elevada proporção da força de trabalho ocupada em atividades formais esse percentual é igual a 27\% em 2010, ligeiramente mais favorável do que o observado em 2000. Essas informações evidenciam que nos centros urbanos, que oferecem maiores oportunidades de trabalho, as mulheres tendem a procurar emprego com mais frequência. As dummies macrorregionais apresentam razões de risco relativas menores do que 01, exceto nas regiões Sul e São Paulo em 2000 e na região Nordeste em 2010. Ou seja, mais recentemente, a região que apresenta maiores estímulos à continuidade da busca pelo emprego, apesar das dificuldades de inserção, é a região Nordeste (a mesma tem crescido a taxas mais expressivas do que a as demais regiões do país, apesar de ainda apresentar indicadores de renda e desenvolvimento menos favoráveis).

Assim, a probabilidade de desocupação é menor para mulheres brancas, escolarizadas e experientes, que residem em microrregiões com elevado rendimento domiciliar per capita e grau de industrialização. Por outro lado, mulheres que residem em áreas mais urbanizadas e com percentuais expressivos de formalização e de qualificação da mão de obra têm maiores dificuldades de inserção; se essas mulheres são responsáveis pelo domicílio, essa probabilidade é ainda maior, pois as mesmas continuam a buscar o ingresso no mercado de trabalho para suprir suas necessidades econômicas.

Os mesmos fatores que contribuem para a desocupação feminina também estimulam a sua escolha pela inatividade econômica. Quanto maior o tempo de permanência na condição ativa e desocupada, maior a probabilidade de essa situação se reverter para a inatividade, especialmente no caso de mulheres que apresentam características não favorecidas pelos mercados de trabalho (negras e baixa escolaridade). Residir em microrregiões mais desenvolvidas (elevados níveis de renda e escolaridade média) pode diminuir essa probabilidade, todavia, quanto mais qualificada a mão de obra local e o nível de formalização dos mercados locais, maior a dificuldade de inserção e, consequentemente, maior a probabilidade de se tornar inativa. A situação econômica de mulheres que moram em regiões pobres também é bastante desfavorável, pois o aumento da taxa de pobreza eleva a probabilidade de inatividade. Cabe ressaltar, por fim, que as mulheres migrantes possuem eleva probabilidade de optar pela inatividade, pois as mesmas podem ter dificuldades de adaptação no destino ou podem estar acompanhando a migração familiar.

\section{Considerações finais}

A dinâmica dos mercados de trabalho brasileiros é bastante diferenciada entre suas regiões, seja em termos salariais, de participação ou de ocupação. Essas diferenças são provocadas pela composição dos próprios mercados de trabalho, cujos participantes possuem características específicas de seus respectivos grupos (homens versus mulheres, negros versus brancos), bem como pelas estruturas produtivas regionais.

O desenvolvimento recente de tecnologias, especialmente de comunica- 
ções e transportes, e o processo de urbanização desempenham papel central na nova organização espacial da produção e têm implicações diretas sobre a condição de ocupação dos trabalhadores, pois em regiões mais populosas, cujas atividades principais são mais intensivas em capital e em serviços sofisticados, a inserção dos mesmos torna-se mais complexa.

Considerada a importância dessas diferenças, este trabalho procurou mensurar a probabilidade de um indivíduo estar ocupado, desocupado ou inativo, realizando controles por intermédio de características individuais e regionais. Além disso, para captar a influência das estruturas regionais, a amostra foi restrita às áreas urbanas e dividida por sexo, para garantir maior homogeneidade ao perfil dos grupos analisados, facilitando assim a identificação da segmentação regional. O procedimento metodológico escolhido para a análise foi a estimação de um modelo de regressão logística multinomial e a base de dados utilizada foi construída a partir dos microdados dos Censos Demográficos 2000 e 2010, fornecidos pelo IBGE. As variáveis incorporadas ao modelo referem-se a atributos individuais produtivos e não produtivos (cor, idade, probabilidade de migração, chefia domiciliar, escolaridade e residência em área metropolitana) e das respectivas microrregiões de residência (média de anos de estudo, rendimento domiciliar per capita médio, taxa de esgotamento sanitário, grau de industrialização, oferta de serviços modernos, proporção da mão de obra qualificada, taxa de formalização, taxa de pobreza e dummies regionais).

Os resultados dos modelos evidenciam a heterogeneidade existente entre homens e mulheres, pois a probabilidade de ocupação masculina é significativamente superior à feminina em todo o período analisado: em 2000, os homens possuíam, em média, $85 \%$ de chances de estarem ocupados, enquanto as mulheres possuíam $50 \%$; em 2010 , esses percentuais se alteraram para $87 \%$ e $61 \%$ respectivamente. As probabilidades de desocupação são similares entre os grupos, mas um pouco mais baixas para os homens $(7,2 \%$ versus $8,6 \%$ em 2000 e $2,8 \%$ versus $4,5 \%$ em 2010 , respectivamente) e as mulheres possuem maiores chances de permanecer na inatividade $(41,4 \%$ versus $7,6 \% \mathrm{em}$ 2000 e $34,4 \%$ versus $9,87 \%$ em 2010 , respectivamente), o que provavelmente é um reflexo de sua dificuldade de inserção (tempo de permanência na desocupação) e/ou de sua escolha entre desempenhar atividades produtivas ou não produtivas (administração do lar). É importante ressaltar que ao longo do período analisado, a participação feminina na população economicamente ativa brasileira cresceu consideravelmente, o que provavelmente é um reflexo da diminuição da segmentação dos mercados de trabalho nacionais por sexo, conforme evidenciam Barros et al. (2007).

Em relação aos atributos pessoais, observa-se que indivíduos que possuem características não produtivas tradicionalmente beneficiadas pelo mercado de trabalho, como a idade e cor, possuem maior probabilidade de ocupação, sejam homens ou mulheres. A qualificação ainda é uma das principais formas de aumentar as chances de conseguir um emprego e a efetivação da migração possui efeitos diversos. No caso dos homens, os indivíduos com elevada probabilidade de migração possuem maior probabilidade de ocupação e de desocupação, o que evidencia a importância da região de destino (a incapacidade de se adaptar ao novo contexto socioeconômico pode dificultar ou atrasar o ingresso no mercado de trabalho). Para as mulheres, a migração diminui a probabilidade de ocupação e aumenta as chances de inatividade. A justificativa para esse resultado provavelmente está atrelada ao fato da migração 
feminina ocorrer no contexto familiar e/ou a sua dificuldade de adaptação ou inadequação ao local de destino. Indivíduos responsáveis pelo domić́lio possuem maiores probabilidades de ocupação e desocupação (para prover as necessidades do lar, os indivíduos procuram emprego mesmo em contextos desfavoráveis).

A importância das estruturas regionais é similar entre os grupos As estimativas da variável indicadora de residência em área metropolitana são o primeiro indício da complexidade inerente aos mercados de trabalho urbanos: elas evidenciam que a probabilidade de ocupação é menor em áreas metropolitanas, enquanto as probabilidades de desocupação e inatividade são mais elevadas, tanto para homens quanto para mulheres. A análise das variáveis indicadoras do nível de desenvolvimento microrregional viabiliza a interpretação desses resultados. Áreas mais dinâmicas em termos educacionais, industriais e de rendimento tendem a ofertar maiores e melhores oportunidades de emprego e renda, tornando mais provável o ingresso no mercado de trabalho. Todavia, à medida que uma região cresce e se desenvolve transformações ocorrem em suas estruturas socioeconômicas, inclusive nos mercados de trabalho, tornando mais complexo o processo de inserção produtiva. Microrregiões mais desenvolvidas e urbanizadas tendem a apresentar maior percentual da força de trabalho com elevada qualificação, maior proporção de trabalhos formais e de ocupações intensivas em capital (serviços modernos). Esses fatores aumentam significativamente a competição por postos de trabalho, diminuindo, assim, a probabilidade de ocupação, especialmente de indivíduos pouco qualificados. Mais uma vez, a educação torna-se a principal medida para minimizar as desvantagens ocupacionais no Brasil.

Nesse contexto, é plausível afirmar que as diferenças entre as estruturas produtivas (micro)regionais têm influências significativas sobre a probabilidade de um indivíduo estar ocupado, desocupado ou inativo, pois a heterogeneidade na composição não produtiva da força de trabalho é insuficiente para explicar essa condição. O nível de desenvolvimento de uma região tem implicações diretas sobre as atividades que nela são desenvolvidas, pois quanto mais denso o centro urbano, mais diversificada é a interação entre os agentes econômicos e, consequentemente, mais facilmente são geradas inovações tecnológicas e sociais (Fujita \& Thisse 2000).

A análise evidencia que os mercados de trabalho podem estar se tornando cada vez mais seletivos e excludentes, o que pode agravar a situação de alguns grupos populacionais, já que os mesmos não conseguem atender os prérequisitos necessários para ocupar a maior parcela dos postos de trabalho que são gerados. É evidente que mesmo nos grandes centros urbanos continuam a existir atividades informais e que não necessitam de qualificação, o que contrabalança em alguma medida essa tendência principal. Todavia, parece haver uma incapacidade do setor urbano de criar empregos em número suficiente para absorver todo o contingente populacional que chega às cidades, atraído por suas facilidades e oportunidades.

\section{Referências Bibliográficas}

Barros, R. P., Franco, S. \& Mendonça, R. (2007), Discriminação e segmentação no mercado de trabalho e desigualdade de renda no brasil, Texto para Discussão 1288, IPEA, Rio de Janeiro. 
Cameron, A. \& Trivedi, P. (2005), Microeconometrics - methods and applications, Cambridge University Press.

Duraton, G. \& Puga, D. (2002), Diversity and specialization in cities: why, where and when does it matter?, in P. McCann, ed., 'Industrial location economics', Cheltenham/Northampton: Edward Elgar.

Fontes, G. G., Simões, R. F. \& Oliveira, A. (2010), 'Urban attributes and wage disparities in brazil: A multilevel hierarchical model', Regional Studies 44(5), 595-607.

Foster, J., Greer, J. \& Thorbecke, E. (1984), 'A class of decomposable poverty measures', Econometrica 52(3), 761-766.

Fujita, M. \& Thisse, J.-F. (2000), The formation of economic agglomerations: old problems and new perspectives, in J.-M. Huriot \& J.-F. Thisse, eds, 'Economics of cities: theoretical perspectives', Cambridge: Cambridge University.

Glaeser, E. L. (1999), 'Learning in cities', Journal of Urban Economics 46(2), 254-277.

Henderson, J. V. (1988), Urban development: theory, fact and illusion, New York, Oxford: Oxford University.

Jacobs, J. (1969), The economy of cities, Middlesex: Penguin Books.

Lima, A., Oliveira, A. \& Simões, R. (2011), Migração e inserção no mercado de trabalho: uma abordagem multinomial para a população economicamente ativa do brasil, in 'XXXIX Encontro Nacional de Economia'.

Marshall, A. (1982), Princípios de Economia, Coleção os Economistas — Nova Cultural, São Paulo.

Marshall, A. \& Wood, P. (1995), Services and space: key aspects of urban and regional development, Longman, London.

Ramos, L. (2007), O desempenho recente do mercado de trabalho brasileiro: tendências, fatos estilizados e padrões espaciais, Texto para Discussão 1255, IPEA, Rio de Janeiro.

Ramos, L. \& Ferreira, V. (2005), 'Geração de empregos e realocação espacial no mercado de trabalho brasileiro - 1992-2002', Pesquisa e Planejamento Econômico (PPE) 35(1), 1-31.

Soares, S. S. D. (2000), O perfil da discriminação no mercado de trabalho homens negros, mulheres brancas e mulheres negras, Texto para Discussão 769, IPEA, Brasília.

Valenzuela, M. E. (1999), Igualdade de oportunidades e discriminação de raça e gênero no mercado de trabalho no brasil, in A. C. Posthuma, ed., 'Abertura e ajuste do mercado de trabalho no Brasil: políticas para conciliar os desafios de emprego e competitividade', São Paulo: Ed. 34. 